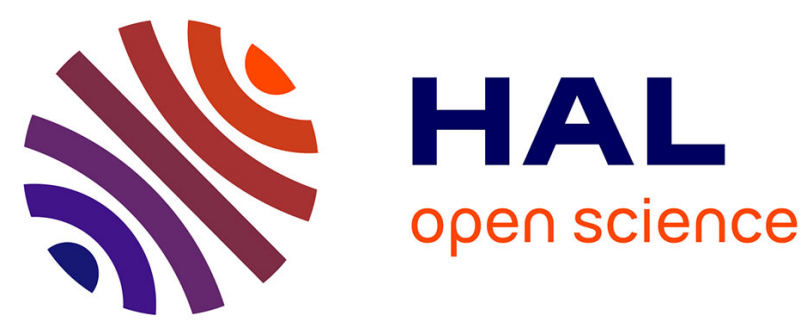

\title{
ON THE BULLWHIP AVOIDANCE PHASE: SUPPLY CHAIN COLLABORATION AND ORDER SMOOTHING
}

Salvatore Cannella, Elena Ciancimino

\section{- To cite this version:}

Salvatore Cannella, Elena Ciancimino. ON THE BULLWHIP AVOIDANCE PHASE: SUPPLY CHAIN COLLABORATION AND ORDER SMOOTHING. International Journal of Production Research, 2009, pp.1. 10.1080/00207540903252308 . hal-00546227

\section{HAL Id: hal-00546227 \\ https://hal.science/hal-00546227}

Submitted on 14 Dec 2010

HAL is a multi-disciplinary open access archive for the deposit and dissemination of scientific research documents, whether they are published or not. The documents may come from teaching and research institutions in France or abroad, or from public or private research centers.
L'archive ouverte pluridisciplinaire HAL, est destinée au dépôt et à la diffusion de documents scientifiques de niveau recherche, publiés ou non, émanant des établissements d'enseignement et de recherche français ou étrangers, des laboratoires publics ou privés. 


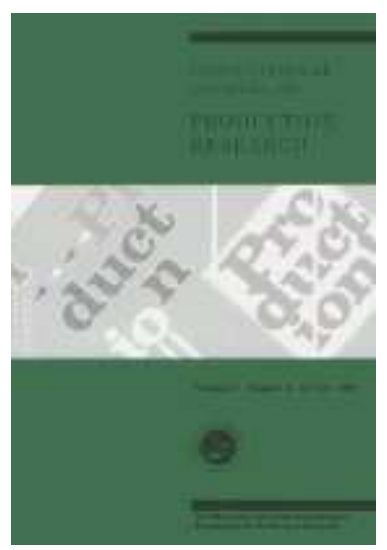

\section{ON THE BULLWHIP AVOIDANCE PHASE: SUPPLY CHAIN COLLABORATION AND ORDER SMOOTHING}

\begin{tabular}{|r|l|}
\hline Journal: & International Journal of Production Research \\
\hline Manuscript ID: & TPRS-2009-IJPR-0174.R1 \\
\hline Manuscript Type: & Original Manuscript \\
\hline $\begin{array}{r}\text { Date Submitted by the } \\
\text { Author: }\end{array}$ & 30 -Jul-2009 \\
\hline Complete List of Authors: & $\begin{array}{r}\text { Cannella, Salvatore; University of Palermo, Faculty of Engineering } \\
\text { Ciancimino, Elena; University of Palermo, Faculty of Engineering }\end{array}$ \\
\hline Keywords: & BULLWIP EFFECT, PERFORMANCE MEASURES \\
\hline Keywords (user): & BULLWIP EFFECT, PERFORMANCE MEASURES \\
\hline &
\end{tabular}

\section{今 ScholarONE" \\ Manuscript Central}




\title{
ON THE BULLWHIP AVOIDANCE PHASE: SUPPLY CHAIN COLLABORATION AND ORDER SMOOTHING
}

\author{
Salvatore Cannella, Elena Ciancimino \\ University of Palermo, Faculty of Engineering \\ viale delle Scienze, Parco d'Orleans, \\ 90128 Palermo, Italy \\ cannella@unipa.it; eciancimino@unipa.it
}

\begin{abstract}
This paper provides an assessment on the impact of collaboration and smoothing replenishment rules on supply chain operational performance and customer service level. Three supply chain configurations (i.e. Traditional, Information Exchange and Synchronised) in which orders are generated by smoothing $(S, R)$ inventory control policies, are studied for variations of proportional controller for different proportional controllers. A supply chain stress test is performed through a sudden and intense change in demand. The main conclusions of this paper are: (i) the impact of Supply Chain Collaboration on overall supply chain performance is higher than that of order smoothing. Order smoothing mitigates bullwhip effect, but it may have negative impact on customer service. Supply Chain Collaboration mitigates the bullwhip effect, provides inventory stability, limits lumpy orders and enhances customer service level. (ii) The negative effect on customer service level of order smoothing is almost eliminated in synchronised supply chains.
\end{abstract}

KEYWORDS: multi-echelon; information sharing; supply chain performance metrics; inventory management; order-up-to periodic review; differential equation modelling; cost reduction strategies

\section{PROBLEM SCOPE}

In 2005, in Budapest, at the Euroma International Conference, Holweg and Disney (2005) identify six distinct developmental stages of the Bullwhip Effect research field:

- pre 1958 the production and inventory control era

- 1958-1969 the production smoothing era

- 1970-1989 the development of control theory

- 1989-1997 the 'beer game' phase

- 1997-2000 the bullwhip rediscovery phase

- since 2000 the bullwhip avoidance phase.

Chen's et al. (2000) coining of Order Rate Variance Ratio as the quantification metric for demand amplification along a supply chain and Cachon and Fisher's (2000) research on the value of information sharing could reasonably be considered the starting point of the current research period devoted to one of the most fascinating Supply Chain Rubik's cubes. One distinctive feature of the Bullwhip Avoidance Phase is the focus toward the efficacy of bullwhip solving approaches. Operation Management community have focused their efforts onto two different approaches for avoiding and/or limiting the bullwhip effect: collaboration in supply chain and smoothing replenishment rules.

Collaboration in supply chain consists in transforming suboptimal individual solutions of individual links into a comprehensive solution through sharing customer and operational information. In the bullwhip avoidance phase several authors showed how supply chain collaboration allows to decelerate the order variability in upstream direction (Chen et al. 2000, Disney and Towill 2002, Chatfield et al. 2004, Kim et al. 2006), reduces inventory holding costs (Shang et al. 2004, Kelepouris et al. 2004, Byrne and Heavey 2006) and improves customer service level (Hosoda et al. 2008).

A smoothing replenishment rule is a periodic review $(S, R)$ inventory control policy where the order is smoothed via proportional controllers. The rationale for this policy is to limit the tiers' overreaction/under-reaction upon changes in demand. Smoothing replenishment rules mitigate bullwhip effect (Dejonckheere et al. 2004, Disney et al. 2004b, Warburton 2004, Jakšič and Rusjan 2008, Kim and Springer 2008) and limit inventory costs (Chen and Disney 2007, Wright and Yuan 2008, Boute et al. 
2009). However, dampening order variability may have negative impact on customer service (Dejonckheere et al. 2003, Disney et al. 2006, Disney et al. 2007, Disney and Lambrecht 2008), as excessive smoothing of order rate could impede to fulfil the marketplace demand in time. This "side effect" on customer service level was mainly shown in supply chains without collaboration mechanisms. The paper attempts to provide a structured assessment on the impact of collaboration and smoothing replenishment rules on supply chain operational performance and customer service level. The research objectives are (i) to contrast the impact of collaboration and the impact of smoothing order rules, and (ii) to show whether the negative effect on customer service of order smoothing rate persists in collaborative supply chain structures.

To fulfil the research objective, three supply chain configurations: i.e. Traditional, Information Exchange and Synchronised (Holweg et al. 2005) in which orders are generated by smoothing $(S, R)$ inventory control policies, are studied for different values of proportional controller. A supply chain stress test is performed via a sudden and intense change in demand ${ }^{1}$. The assessment system is based on two criteria: "supply chain operational performance" and "customer service level" and taking into account both local (single echelon) and systemic performance (supply chain) measures. Supply chains are modelled by differential equations.

The main results are: (i) the impact of Supply Chain Collaboration is higher than that of order smoothing on the overall supply chain performance. Order smoothing mitigates bullwhip effect, limits inventory variability and lumpy orders, but, as showed in literature and reasserted in this work, it may have a negative impact on customer service. Supply chain Collaboration avoids bullwhip effect, provides inventory stability and enhanced customer service level. (ii) The negative effect on customer service level of order smoothing is almost avoided in collaborative supply chain.

The paper is organised as follows. In Section 2 supply chain collaboration and smoothing replenishment rules are briefly discussed. Section 3 presents the three studied supply chain archetypes. Section 4 reports the methodological approach and the mathematical formalism of the supply chain models. Section 5 is devoted to describe the measurement system. In Section 6 the experimental design is detailed. Technical discussions are presented in section 7 and results are reported in section 8. Finally, Section 9 provides conclusions.

\section{BULLWHIP AVOIDANCE PRACTICES: SUPPLY CHAIN COLLABORATION AND SMOOTHING REPLENISHMENT RULES AT A GLANCE}

The inventory replenishment rule and Supply Chain Collaboration as bullwhip avoidance practices are presented in the following sub-sections.

\subsection{Supply Chain Collaboration}

The word collaboration originates from the Latin cum-laborare: act of working jointly. Supply Chain Collaboration refers to the shared efforts made by members to achieve a common goal. The shared effort is to transform suboptimal individual solutions of individual links in the supply chain into a comprehensive solution (Seifert 2003). The common goal of collaboration is the elimination of inefficiencies, such as the bullwhip effect ${ }^{2}$, which occur through uncoordinated sequences in the supply chain. Visibility of information flow is the key enabler of members' coordination: the Holy Grail of supply chain (Holweg et al. 2005).

Since the 1980s, when the Quick Response programme was introduced in apparel firms (Hunter 1990), large-scale collaboration projects have gradually modified the modus operandi in global supply chains ${ }^{3}$. The implementation of collaboration projects has reshaped material and information flows, intensified alliances and transformed strategies, organisations and corporate culture. These structural changes have

\footnotetext{
1 In 2007 Towill et al. presented a creative classification framework for bullwhip studies. They identified three "observer's perspectives" to analyse the bullwhip effect: Variance lens, Shock lens and Filter lens. Using a mathematical modelling, the bullwhip shock lens aims to infer on the performance of supply chains for an unexpected change in marketplace demand. This approach can be viewed as a "crash test" or a "stress test": studying the system performance under an intense and violent solicitation.

2 Barilla (Hammond 1994), Campbell (Cachon and Fisher 1997), Procter \& Gamble and Hewlett-Packard (Lee et al. 1997), WalMart (Waller et al. 1999), 7-Eleven (Lee 2004), Philips (De Kok et al. 2005) are outstanding examples of successful supply chain collaboration implementations. Furthermore, several mathematical models have showed the efficacy on supply chain collaboration in terms of bullwhip dampening, inventory variance reduction and customer service level improvement. Table 1 reports a nonexhaustive list of contributions to the topic in the bullwhip avoidance phase.

${ }^{3}$ Large-scale projects are specific initiatives of Supply Chain Collaboration. Notorious large-scale projects are efficient consumer response (McKinsey \& Co. 1992), vendor managed inventory (Cachon and Fisher 1997, Disney and Towill 2003b), continuous replenishment (Andraski 1994), collaborative planning, forecasting and replenishment (VICS 1998, Holmström et al. 2002), centralised inventory management (Lee et al. 1997).
} 


\subsection{Smoothing Replenishment Rule}

In production-inventory systems, order timing and quantity are defined by a coordinated set of "rules and procedures" that allows for routing decision on "when" and "how much" to order for each item needed in the manufacturing or procurement process to fill customer demand, while maintaining inventories at the "right" level (Hax and Candea 1984). These rules and procedures in inventory control systems are commonly known as replenishment policies. A standard classification of order quantity control policies is based on the timing of the inventory review: Continuous Review Systems versus Periodic Review Systems. If ordering costs are relatively high when compared to the inventory review costs and/or supplier accepts orders only with a given frequency (daily, weekly, monthly), the periodic review system is essentially more desirable (see e.g. Hax and Candea 1984, Disney and Lambrecht 2008).

In practical applications the most largely used periodic review policy is the $(S, R)$ order rule (Hax and Candea 1984). Each review period $R$ the inventory is reviewed and a quantity $O$ is ordered to bring the level of the available inventory up to a level $S$, known in the literature as order-up-to level. The available inventory consists of the inventory on hand plus the inventory on order but not yet arrived (pipeline inventory or work in progress) (Disney and Lambrecht 2008). The $S$ level is dynamically computed every period $R$ as the sum of the forecast on the customer demand, plus a target on-hand inventory, plus a target pipeline inventory. The quantity $O$ is generated to satisfy the customer demand, and to fill entirely the gap between the target and the current levels of on-hand inventory, as well as the gap between the target and the current levels of the pipeline inventory.

A smoothing replenishment rule is a $(S, R)$ policy in which the entire deficit between the $S$ level and the available inventory is not recovered in a review period. For each review period $R$ the quantity $O$ is generated to recover only a fraction of the gap between the target on-hand inventory and the current level of on-hand inventory, and a fraction of the gap between the target pipeline inventory and the current level of pipeline inventory. The amount of the gaps to recover is regulated by decision parameters known as

\footnotetext{
4 Supply chain collaboration has been defined through a number of dimensions (Bailey and Evans 2006) such as information integration, synchronised planning, work flow coordination, new business models (Lee and Whang 2003); information sharing, decision synchronisation, incentive alignment (Simatupang and Sridharan 2004); cross functionality, process alignment, joint decision making, shared performance metrics (Barratt 2004).

5 Smoothing replenishment rules are also known as Inventory and Order Based Production Control System (IOBPCS) order policies (Coyle 1977). The features of smoothing replenishment rules were studied and popularised by the Cardiff Business School (see Towill 1982, John et al. 1994, Disney and Towill 2006). For an extensive discussion on smoothing replenishment family see Lalwani et al. (2006) and Sarimveis et al. (2008).
} 
proportional controllers $^{6}$. The inventory proportional controller Ty modulates the recovery of the onhand inventory gap and the work in progress proportional controller $T w$ determines the recovery of the pipeline inventory gap ${ }^{7}$. A particular class of smoothing $(S, R)$ is the matched controller case (Disney and Towill 2002, 2006, Disney et al. 2004), known as Deziel and Eilon setting (Deziel and Eilon 1967). It refers to the case in which the inventory proportional controller $T y$ is equal to the work in progress proportional controller $T w$.

The smoothing replenishment can be definitely considered one of the major topics in the Bullwhip Avoidance Phase, as it is an effective remedy to demand signal processing, a cause described by Lee's et al. (1997), see Table 1. The rationale for this order policy is to limit the tiers' over-reaction/underreaction for changes in demand. In the literature it is shown that properly tuning the value of the proportional controllers in the smoothing $(S, R)$ policy offers an opportunity to reduce bullwhip (Disney and Towill 2003a, Disney et al. 2007) at a lower cost than holding extra inventory (Chen and Disney 2007). In particular, the Deziel and Eilon configuration was shown to be a particularly stable setting for proportional controllers (Disney and Towill 2006). However, smoothing replenishment rules may have negative impact on customer service (Dejonckheere et al. 2003, Disney et al. 2006, Disney et al. 2007, Disney and Lambrecht 2008), as excessive smoothing of the order rate could impede to fulfil the marketplace demand in time. This "opposite trend" between bullwhip reduction and customer service level was mainly shown in no collaborative supply chains. In Appendix 2 a hydraulic analogy is presented to clarify the effect on performance of order smoothing. Table 1 reports a non-exhaustive list of authors that inferred on the impact of collaboration and order smoothing in the Bullwhip Avoidance Phase.

\section{TABLE 1}

\footnotetext{
6 In the literature, proportional controllers have been defined with different appellatives, e.g. adjustment time (Forrester 1961, Sterman 1989, Warburton 2004), fraction of the inventory and wip discrepancy (John et al. 1994), time to adjust for wip and net stock errors (Dejonckheere et al. 2004), proportional inventory position feedback gain (Disney and Grubbström 2004), fraction of the inventory deficit (Boute et al. 2007), smoothing parameter (Jakšič and Rusjan 2008) or feedback gain (Disney and Lambrecht 2008).

7 In the $(S, R)$ policy, proportional controllers can be thought of amplifiers or attenuators (Disney et al. 2007). The proportional controllers of a smoothing replenishment rule are attenuators, as they are set to recover a fraction of the inventory deficits. In the mathematical formalisation of smoothing replenishment rules, proportional controllers can be "divisors" or "multipliers" of the inventory gaps. When they are "divisors" their value is greater than 1 . When they are "multipliers" their value is a positive number less than 1 . When they are equal to 1 order policy turns to a classical $(S, R)$.
} 


\section{SUPPLY CHAIN MODELS: INFORMATION FLOW AND REPLENISHMENT DECISION}

To infer on the impact of collaboration and the impact of smoothing replenishment rules, three levels of increasing collaboration represented by three Holweg's et al. (2005) supply chain archetypes, in which orders are generated by smoothing $(S, R)$, are modelled:

I. Traditional Supply Chain

II. Information Exchange

III. Synchronised Supply

The presented models are unconstrained capacity $K$-stage single-product ${ }^{8}$ production-distribution serial systems with a unidirectional flow of material. The generic echelon's position is represented by index $i$. Echelon $i=1$ stands for the manufacturer and $i=K+1$ for the final customer. Figure 1 shows the flow of materials for the three configurations. Nomenclature for variables is reported in appendix A.

Figure 1. Flow of materials in the supply chains

The configurations differ in the information flow and in the use of information to generate the smoothing replenishment rule. In the following subsection the shared data and the order policies are presented in detail.

\subsection{Traditional Supply Chain}

In the traditional supply chain the information flow consists in the mere transmission of members' orders upstream. A generic echelon $i$ only receives information about order quantity $O_{i+1}$ from the downstream adjacent echelon (Figure 2).

Figure 2. Traditional Supply Chain

Each generic echelon $i$ generates the order quantity $O_{i}$ on the basis of local data and parameters (Inventory level $I_{i}$, local Work in progress level $W_{i}$, safety stock factor, lead time and proportional controllers $T y$ and $T w$ ) and on the incoming orders from the downstream adjacent echelon $O_{i+1}$. The order quantity $O_{i}$ (equation 1 ) is the sum of the following components:

- forecast on the order from the subsequent echelon $\hat{d}_{i}$

- $\quad$ smoothed work in progress gap

- $\quad$ smoothed inventory gap

$$
O_{i}(t)=\hat{d}_{i}(t)+\frac{1}{T w_{i}}\left(T W_{i}(t)-W_{i}(t)\right)+\frac{1}{T y_{i}}\left(T I_{i}(t)-I_{i}(t)\right)
$$

Echelon $i=K$ forecasts customer demand $\hat{d}_{K}$ on the basis of markets sales $d$, and the remaining echelons only take into account downstream incoming orders $O_{i+1}$ for their forecast $\hat{d}_{i}$.

\subsection{Information Exchange}

In the information exchange supply chain the information flow consists on the transmission of members' orders in up-stream direction and on sharing the information on market demand. A generic echelon $i$ receives information on the order quantity $O_{i+1}$ from the downstream adjacent echelon and on the up-todate market demand $d$ (Figure 3).

Figure 3. Information Exchange Supply Chain

\footnotetext{
8 The single-product modelling assumption is widely used in bullwhip analysis. The application of Laplace transform and $\mathrm{Z}$ transform to production inventory control (Simon 1952, Vassian 1955), the mono-step numerical method to analyse the demand amplification phenomenon (Forrester 1961), the management games performed at Mit to investigate the human behaviour in supply chain (Sterman 1989), the formalisation of the widely-known "four causes" of the bullwhip effect (Lee et al. 1997), the generation of the Order Rate Variance Ratio (Chen et al. 2000), cornerstones in the inventory control field, are based on the single-product assumption. Specifically, within the bullwhip avoidance phase literature, Dejonckheere et al. (2003), Disney and Towill (2003a), Chandra and Grabis (2005), Gonçalves et al. (2005), Boute et al. (2007), Hosoda and Disney (2006), Ouyang (2007), Aggelogiannaki et al. (2008), Agrawal et al. (2009) can be cited.
} 
A generic echelon $i$ generates the order quantity $O_{i}$ on the basis of local data and parameters, incoming orders $O_{i+1}$ and market demand $d$.

The order quantity $O_{i}$ (equation 2 ) is the sum of the following components:

- forecast on market demand

- $\quad$ smoothed work in progress gap

- $\quad$ smoothed inventory gap

$$
O_{i}(t)=\hat{d}_{K}(t)+\frac{1}{T w_{i}}\left(T W_{i}(t)-W_{i}(t)\right)+\frac{1}{T y_{i}}\left(T I_{i}(t)-I_{i}(t)\right)
$$

Unlike a traditional supply chain, all echelons receive information on market demand $d$ in the information exchange. The customer's demand forecast $\hat{d}_{K}$ is directly included in the replenishment rule, while, as in the traditional, the forecast on orders incoming by echelon $i+1 \hat{d}_{i}$, is used to compute Target Work in Progress (equation 12) and Target Inventory (equation 13).

\subsection{Synchronised Supply}

In the synchronised supply chain the information flow consists in the transmission of members' orders, Inventory levels, Work in progress levels, lead times and safety stock factors upstream and in sharing the information on market demand. A generic echelon $i$ receives information about order quantity $O_{i+1}$ from the downstream adjacent echelon, on the up-to-date market demand $d$ and Safety stock factors $T_{c_{j}}$, Lead Times $T_{p}$, Inventory levels $I_{j}$, and Work in progress Levels $W_{j}$ from all downstream echelons $j=i+1 \ldots K$ (Figure 4).

\section{Figure 4. Synchronised Supply Chain}

The order quantity $O_{i}$ (equation 3 ) is the sum of the following components:

- forecast on market demand

- $\quad$ smoothed Multi-echelon work in progress gap

- $\quad$ smoothed Multi-echelon inventory gap

$$
O_{i}(t)=\hat{d}_{K}(t)+\frac{1}{T w_{i}}\left(T v W_{i}(t)-v W_{i}(t)\right)+\frac{1}{T y_{i}}\left(T v I_{i}(t)-v I_{i}(t)\right)
$$

Unlike traditional and information exchange, synchronised supply chain is a centralised structure in which any echelon considers its successors as part of its inventory system ${ }^{9}$ for determining replenishment quantity. While in the previous configurations Target Inventory and Target Work in progress are functions of the echelon local data, in the synchronised supply chain both current and target levels of Inventory and Work in progress at echelon $i$ also take into account data incoming from all downstream echelons. Table 2 summarises the differences in incoming data and Table 3 details the components of the replenishment in the three supply chains, respectively.

Table 2. Incoming data for a generic echelon $i$ in the different supply chain configurations

Table 3. Components of smoothing replenishment rules

\section{METHODOLOGICAL APPROACH AND MATHEMATICAL FORMALISM}

The operations management literature is rich in classifications of methodologies used to investigate supply chain performance and the bullwhip phenomenon (Riddalls, et al. 2000, Kleijnen and Smits 2003,

\footnotetext{
9 The inclusion of successors' inventory levels into the replenishment decision dates back to the 50s. Disney and Towill (2003c) report that the concept was initially discussed by Magee (1958), in a presentation of a conceptual framework for designing a production control system, pointed by the authors as the pioneer model of Vendor Managed Inventory. Two years later, the publication of Clark and Scarf (1960), recognised as the seminal work in multi-echelon inventory analysis (Whang 1995, Dong and Lee 2003, Swaminathan and Tayur 2003, DeCroix 2006) could be reasonably considered the first mathematical formalisation for a fully coordinated decision-making approach (Sahin and Robinson Jr. 2005).
} 
Dejonckheere et al. 2004, Disney et al. 2004a, Geary et al. 2006, Towill et al. 2007, Disney and Lambrecht 2008).

A classification of methodological approaches for supply chain analysis from the perspective of decision making hierarchical level was provided by Riddalls et al. (2000). They identify two main approaches: "OR techniques" and "methodologies based on the dynamics of system". According to their framework, OR techniques have their place at a local tactical level in the design of supply chains and in day-by-day decision making, while the implication of strategic design on supply chain performance and the global network functioning are better analysed by using methodologies based on the dynamics of system (continuous time differential equation models, discrete time difference equation models, discrete event simulation systems).

In the Bullwhip Avoidance Phase Holweg and Disney (2005) clarified the latter methodological approach for supply chain analysis. They recognised three distinct and methodologically independent research domains: the discrete time approach, the continuous time approach and the control theory approach. The authors affirmed that Herbert Simon (1952) and Jay Forrester (1961) laid the foundations to the continuous time domain approach towards the study of supply chain dynamics. The Nobel Prize discussed the application of linear deterministic control theory to production control, by using Laplace transform techniques (Axsäter 1985), while Forrester adopted solution methods for the initial-value problem of nonlinear repeated coupling of first-order differential equation systems. The numerical methods used to approximate a solution for the initial-value problem are generally mono-step, such as Euler-Cauchy method (tangent or constant-slope), Kutta's method, trapezoidal integration method, and Heun method (three-term Taylor series), or multi-step, such as Adams-Bashfort method, and AdamsMoulton method. Several mathematical toolboxes designed to solve a broad range of problems or ad-hoc applications (such as Vensim, ithink, DYNAMO and Powersim) can be used to approximate the solution of differential equations.

The methodological approach adopted in this paper is based on the dynamics of system, namely the continuous time approach. The supply chain configurations are modelled through first-order nonlinear differential equations. The mathematical formalism of the supply chain configurations studied in this work is reported in Tables 4 and 5.

Table 4. Equations

Table 5. Supply Chain Configurations and related Equation System

\section{MEASUREMENT SYSTEM}

Performance measurements are used to determine the efficiency and effectiveness of an existing system, or to compare alternative systems (Neely et al. 1995). Performance measures are also used to design proposed systems, by determining the values of the decision variables that yield the most desirable level of performance (Beamon 1999). Supply chain performance metrics have been classified on the basis of several criteria: financial vs. non-financial (De Toni and Tonchia 2001), qualitative vs. quantitative (Gunasekaran et al. 2001), strategic/tactical/operational (Gunasekaran and Kobu 2007), and functionbased vs. value-based (Bagchi 1996).

The bullwhip effect is a multifaceted and extremely complex phenomenon that impacts on operational, tactical and strategic aspects of performance: order-production-distribution efficacy, operational and customer responsiveness, service level, holding investments and costs, flexibility. Due to the polyhedral impact of bullwhip, the scientific community has recently advocated for multidimensional analyses of supply chain and bullwhip phenomenon through the adoption and development of suitable performance measures and comprehensive metrics systems (Towill et al. 2007, Gunasekaran and Kobu 2007).

According to the recent literature, a structured and extended supply chain assessment framework is adopted to respond to the problem scope of this work. It is based on two criteria: "operational performance" and "customer service level" and it measures both local (single echelon) and systemic performance (supply chain). The operational performance is measured through a set of metrics, whose reduction reflects improved cost effectiveness of members' operations. Customer service level is assessed by the widely adopted fill rate, whose increase expresses reduced backlog and decreased stock-out costs. In Table 6 referenced and herein propounded metrics are classified and associated to the related information content and costs.

Table 6 Measurement System 


\section{Order Rate Variance Ratio}

This metric was proposed by Chen et al. (2000) and is so far the most common bullwhip measure in the literature (Disney and Lambrecht 2008). Disney and Towill (2003a) noted that, for a stationary random signal, over long periods of time the means cancel out as $\mu_{o}=\mu_{d}$. Order Rate Variance Ratio is the quantification of the instability of orders in the network (indexes are reported in Table 7).

$$
O R V r R_{m, i}=\frac{\sigma_{O_{m, j}}^{2} / \mu_{O_{m, i}}}{\sigma_{d}^{2} / \mu_{d}}
$$

\section{Inventory Variance Ratio}

This metric was proposed by Disney and Towill (2003a) to measure net stock instability, as it quantifies the fluctuations in inventory. An increased inventory variance results in higher holding and backlog costs ${ }^{10}$, inflating the average inventory cost per period (Disney and Lambrecht 2008).

$$
I V r R_{m, i}=\frac{\sigma_{I_{m, i}}^{2} / \mu_{I_{m, i}}}{\sigma_{d}^{2} / \mu_{d}}
$$

\section{Average Inventory}

Average inventory is the mean of a tier's Inventory values over the interval $T$. The metric is commonly used in production-distribution system analysis in order to provide concise information on inventory investment, see e.g. holding cost modelled as linearly dependent from stock levels in Cachon and Fisher (2000), Disney and Grubbström (2004), Shang et al. (2004), Chen and Disney (2007), Reichhart et al. (2008), Wright and Yuan (2008).

$$
A I_{m, i}=\frac{1}{T} \sum_{i=0}^{T} I_{m, i}(t)
$$

\section{Systemic Average Inventory}

Systemic Average Inventory (Cannella and Ciancimino 2008, Ciancimino and Cannella 2009) is the sum of the Average Inventory values of all tiers in a given supply chain configuration. Summing inventory levels all along supply chain is a well-established industrial practice. Compaq Computer and Procter \& Gamble routinely measure both their own inventory and downstream inventory at their distributors (Hausman 2003).

$$
S A I_{m}=\sum_{i=0}^{K} A I_{m, i}
$$

\section{Fill Rate}

Fill Rate is representative of customer service level (Zipkin 2000). The Fill Rate is evaluated every single $\Delta t$ and computed on the sales to the ultimate customer. Although the metric is based on the information of one level of the supply chain (echelon $K$ ), it captures the performance of all partners, since the service to the final customer is the end purpose of the entire supply chain (Hausman 2003).

$$
F R_{m}(t)=\frac{C_{m, K}(t)}{d(t)}
$$

\section{Average Fill Rate}

The Average Fill Rate is the mean of a subset of Fill Rate values computed over a limited time interval $\Gamma \subseteq T$. The interval $\Gamma$ is selected by considering, among all numerical simulations $\Omega$, the longest time span $\left[\tilde{\tau}^{\prime \prime}-\tilde{\tau}^{\prime}\right]$ with Fill Rate values lower than 1, that is: the maximum duration of shortage. This procedure permits to analyse the production-distribution network only during stock-outs and to compare the magnitude of backlog among the different the supply chain structures and parameter settings. The problem of quantifying the stock-out costs is a difficult and unsatisfactorily solved question in inventory theory, especially because of the intangible components (Hax and Candea 1984). The adoption of a limited time interval $\Gamma$ to compute the customer service level is related to a widely used assumption to estimate the stock-out cost as proportional to the product of the number of units out of stock and the duration of stock-outs, such as in Holt et al. (1960).

$$
\begin{aligned}
& A F R_{m}=\frac{1}{\Gamma} \sum_{t=\tilde{\tau}^{\prime}}^{\tilde{\tau}^{\prime \prime}} F R_{m}(t) \\
& \Gamma=\max _{\omega}\left(\tau_{m}^{\prime \prime}-\tau_{m}^{\prime}\right)=\tilde{\tau}^{\prime \prime}-\tilde{\tau}^{\prime}
\end{aligned}
$$

\footnotetext{
10 Inventory variance ratio is representative of backlog cost if the modelling allows negative inventory. In this work the non-negative condition of inventory is assumed and the Inventory Variance Ratio reflects increased holding cost per unit, missing production schedules costs, utilisation of transport capacity costs. Backlog costs are identified by Fill Rate.
} 


\section{Zero-Replenishment}

For $(S, R)$ order policy, the Zero-Replenishment Phenomenon is defined as the event in which, in a review period $R$, a tier does not place any order (Cannella and Ciancimino 2008, Ciancimino and Cannella 2009).

An order pattern characterised by a significant number of Zero-Replenishment Phenomena is known in literature as sporadic, intermittent or lumpy (Silver 1970, Croston 1972, Schulz 1987, Chatfield and Hayya 2007).

In a given time horizon, if the demand is a positive and stationary signal and the parameters of the inventory replenishment rule remain unaltered, the occurrence of the Zero-Replenishment Phenomenon could be indicative of an erroneous excessive dimensioning of previous orders.

The Zero-Replenishment metric is the total amount of the Zero-Replenishment Phenomenon occurrences in the observation period $T$. The metric is used to measure timely and pondered reactivity and scalability of tier's operations. Zero-Replenishment cannot be viewed as a stand-alone supply chain performance metric and it shall be analysed together with a customer service level measure: apparently, null or low Zero-Replenishment values could be indicative of optimal operations and lot sizing, but this is true only when at the same time the system assures a high customer service level. Otherwise, a poor customer service level associated to a null or low ZeroReplenishment reflects poor system responsiveness.

$$
\begin{aligned}
& Z R_{m, i}=\sum_{i=0}^{T} x_{m, i}(t) \\
& x_{m, i}(t)= \begin{cases}1 & O_{m, i}(t)=0 \\
0 & O_{m, i}(t) \neq 0\end{cases}
\end{aligned}
$$

\section{Systemic Zero-Replenishment}

The Zero-Replenishment phenomenon can be evaluated at a systemic level referring to a Systemic ZeroReplenishment, computed as the sum of the Zero-Replenishment of the single echelons in a given supply chain configuration.

$$
S Z R_{m}=\sum_{i=1}^{K} Z R_{m, i}
$$

Proportional Controller Bullwhip Slope and Proportional Controller Inventory Instability Slope

Dejonckheere et al. presented in 2004 a study on the dynamic behaviour of four-tier multi-echelon supply chains. They adopted the Order Rate Variance Ratio to assess and compare different bullwhip solution approaches. In order to contrast various supply chain configurations, they plotted the obtained values using the echelon position as an independent variable. They observed the interpolated curve and inferred qualitatively about the linear or geometric nature of the trend. The authors state that a geometric increase of the Order Rate Variance Ratio interpolating curve is representative of strong bullwhip propagation, more intense than in a linear trend. Dejonckheere's et al. curve is a smart representation of bullwhip propagation in a multi-echelon system and permits to concisely compare different supply chain configurations (Cannella et al. 2008, Cannella and Ciancimino 2008). To extend Dejonckheere's et al. inferring technique to a general case, a statistical analysis of the curve could be performed for both Order Rate Variance Ratio and Inventory Variance Ratio.

Adopting an analogous approach, a similar curve can be obtained for a single echelon using the matched proportional controller as the independent variable. In this case the curve is a compact representation of the echelon's sensitivity to bullwhip for proportional controller variations within a given range. Under the assumption of linearity, a first-order regression can be performed in order to compare the echelon's sensitivity for different supply chain configurations on the basis of the linear regression coefficient, named Proportional Controller Bullwhip Slope.

To obtain a graphical representation of echelon's sensitivity to the proportional controller in a given supply chain configuration (in this work Traditional, Information Exchange and Synchronised), the slope values are reported in a radar diagram. Each axis of the radar represents an echelon, and the value on the axis is the respective Proportional Controller Bullwhip Slope. The larger the radar area, the greater the impact of a proportional controller variation on the given configuration in terms of Order Rate Variance Ratio.

This procedure can be analogously performed for Inventory Variance Ratio. In this case the linear regression coefficient is named Proportional Controller Inventory Instability Slope and the effect of parameter variations on the net stock fluctuations is the scope of the analysis.

\section{EXPERIMENTAL DESIGN}

Three levels of collaboration and three levels of order smoothing are studied. The $M$ levels of collaboration are represented by the three supply chain configurations detailed in the previous sections, the $N$ levels of smoothing order depend on three settings of the matched proportional controller $T_{y}=T_{w}$ (Deziel and Eilon setting). The total number of experiments $\Omega$ is the product of the number of levels for order smoothing $N$ and the number of supply chain configurations $M$ (Table 7). In order to isolate the effect of collaboration and order smoothing, the 
parameters lead time, safety stock factor and demand smoothing forecast are not varied throughout the $\Omega$ experiments.

Table 7. Indexes

In this work the numerical experiments are performed under the following settings:

- $\quad$ The serial systems are composed by $K=4$ echelons.

- The $M$ levels of collaboration are represented by the three supply chain configurations, Traditional, Information Exchange, Synchronised.

- The $N$ levels of order smoothing are identified by the following matched proportional controller designs $^{11}$, presented in ascending order of smoothing:

$$
\begin{aligned}
& T y=T_{w}=T_{p} \\
& T y=T w=T p+1 \\
& T y=T w=2 T_{p}
\end{aligned}
$$

- $\quad$ The values of lead time, safety stock factor and demand smoothing forecast factor are: $\left[T_{p_{i}}, T_{c_{i}}, \alpha_{i}\right]=[2$, 3, 0.33] $\forall i$.

- The actual marketplace demand $d$ is initialised at 4 units per time unit, until there is a pulse at $t=5$, increasing the demand value up to 8 units per time unit (Sterman 1989). The step demand pattern $d(t)$ is assumed to perform a stress test according to Towill's et al. "shock lens" perspective (2007).

- The values of the initial state variable values are: $\left[W_{i}(0), I_{i}(0), B_{i}(0)\right]=\left[T p_{i} d(0), \mathrm{Tc}_{i} d(0), 0\right] \forall i$.

- $\quad$ The numerical experiments $\Omega$ are performed for a time length $T=52$.

- The solutions for the initial-value problem are approximated through Vensim PLE. The Euler-Cauchy method with order of accuracy $\Delta t=0.25$ is adopted.

The numerical experiment output is next presented. In Tables 8 and 9 Order Rate Variance Ratio and Inventory Variance Ratio are reported, respectively. Results are reported by echelon (row), and by supply chain configuration (column), grouped by matched proportional controller level.

Table 8. Order Rate Variance Ratio

Table 9. Inventory Variance Ratio

Proportional Controller Bullwhip Slope and Proportional Controller Inventory Instability Slope are reported in Figure 5. Each axis of the radar represents an echelon, and the value on the axis is the Proportional Controller Slope for that echelon. These values are indicative of the echelon's sensitivity to variations in smoothing parameters within the studied range. The radar areas are representative of the magnitude of the impact of a matched proportional controller variation on the given configuration in terms of Order Rate Variance Ratio and Inventory Variance Ratio.

Figure 5. Proportional Controller Bullwhip Slope and Proportional Controller Inventory Instability Slope

Average Inventory is reported according to Dejonckheere's et al. notation (2004) in Figure 6. The output values are plotted using the echelon position as the independent variable. Each diagram groups supply chain configuration for the three values of matched proportional controller.

Figure 6. Average Inventory

Zero-Replenishment values are reported in Figure 7. Results are displayed by echelon, by supply chain configuration and by matched proportional controller.

\section{Figure 7. Zero-Replenishment}

Average Fill Rate, Systemic Average Inventory, and Systemic Zero-Replenishment are presented in Figure 8. The horizontal bar chart represents the Average Fill Rate; the histogram stands for the Systemic Average Inventory, and the column with cylindrical shape represents the Systemic Zero-Replenishment. The numerical value for each metric is reported next to the corresponded diagram.

\footnotetext{
11 In the literature several settings of matched (Naim and Towill 1995, Disney et al. 2001, Disney et al. 2007) and unmatched (Disney et al. 1997, Hong Ming et al. 2000, Wright and Yuan 2008) proportional controller designs have been tested. In this work the proportional controller experimental levels are related to lead time. Equation (28) and (30) are from proportional controllers design of John et al. (1994), equation (29) refers to Disney and Towill (2006).
} 


\section{DISCUSSIONS}

Results are analysed by supply chain configuration in the following subsections and then summarised in Section 9.

\subsection{Traditional Supply Chain}

The results from the study indicate that, in the Traditional configuration, order smoothing strongly impacts on performance.

Traditional supply chain shows bullwhip effect for every design of proportional controllers under an unexpected variation in market demand. This result is in line with Chatfield's et al. (2004) and Dejonckheere's et al. (2004) conclusions: traditional supply chain exhibits a geometrical increase of order variance in up-stream direction for the three studied levels of order smoothing. The difference in the three order smoothing levels consists of the magnitude of bullwhip, strongly lowered for increasing smoothing. Results also reconfirm Disney's et al. conclusion (2004): bullwhip magnitude is monotonically reduced for increasing order smoothing. Results show a reduction of order variability for echelon $i=1$ from 345 to 92 shifting from the low smoothing level $\left(T_{y}=T_{w}=T_{p}\right.$ design) to the high smoothing level ( $T_{y}=T_{w}=2 T_{p}$ design).

Inventory Variance Ratio and Average Inventory show the same trend that Order Rate Variance Ratio: fluctuation and average levels of inventory are high for all smoothing settings, however the two related metrics decrease for increasing order smoothing levels. Systemic Average Inventory decreases from $48 \%$ to $66 \%$ for increasing order smoothing values. Differences emerge in node-to-node increase of Inventory Variance Ratio with respect to the Order Rate Variance Ratio trend. Echelon $i=1$ (manufacturer) shows a lower value Inventory Variance Ratio than its subsequent $i=3$. This phenomenon is due to the unlimited raw material supply assumption.

Zero-Replenishment indicates sporadic order occurrence in the traditional supply chain for all smoothing levels. The metric shows the same trend of all previous measures, decreasing for increasing order smoothing; lumpy orders are not eliminated by proportional controller in traditional supply chains.

On the contrary, Fill Rate has an opposite trend with respect to operational performance metrics: a monotonically decrease of customer service level for increasing order smoothing. Shifting from a low smoothing to a high smoothing, Average Fill Rate decreases from $82.5 \%$ to $77.5 \%$. This result confirms literature conclusions for traditional supply chain on the relation between order smoothing and customer service level (Dejonckheere et al. 2003, Disney et al. 2006, Disney et al. 2007, Disney and Lambrecht 2008).

To sum up:

I. Traditional supply chain exhibits a geometrical increase of order variance in up-stream direction, high inventory variability and intermittent order phenomenon. The magnitude of the noxious phenomena is strongly related to the order smoothing levels.

II. As order smoothing increases, the supply chain operational performance improves (Inventory variance ratio, Average Inventory, Zero-Replenishment) but the customer service level worsens (Fill Rate). Smoothing the order rate noticeably limits the magnitude of bullwhip effect but it can result in poor customer service.

III. The smoothing parameter variations significantly impact on performance of traditional supply chains

\subsection{Information Exchange}

In Information exchange supply chain, the bullwhip effect decelerates upstream with respect to the traditional structure. However, bullwhip effect is not completely eliminated even after sharing market information as in Agrawal et al. (2009). As in Chatfield et al. (2004) and Dejonckheere (2004), information exchange supply chain exhibits a linear increase of order variance in up-stream direction for the three studied levels of order smoothing. As in the Traditional supply chain, the difference in the supply chain response to the three smoothing order levels is the magnitude of bullwhip, strongly reduced for increasing smoothing parameters.

More specifically, a noticeable reduction of bullwhip is showed for echelon $i=1$ shifting from low smoothing ( $T_{y}=T_{w}=T_{p}$ design) to medium smoothing $\left(T_{y}=T_{w}=2 T_{p}\right.$ design), in which the value of Order Rate Variance Ratio goes from 145 to 37. Inventory Variance Ratio, Average Inventory and Zero-Replenishment show the same trend of Order Rate Variance Ratio: as smoothing order increase, supply chain operational performance improves. Systemic Average Inventory decreases from $47 \%$ to $56 \%$ for increasing smoothing values and lumpy orders are reduced. Although the operational performance in information exchange has the same trend than in traditional supply chains for variations of the order smoothing level, in this case the gradient is less steep and the values of the metrics reveal a better performance. The radar areas of Proportional Controller Bullwhip Slope and Proportional Controller Inventory Instability Slope show that echelons' sensitivity to proportional controller variation is still noticeable, but the impact is reduced with respect to the Traditional configuration. 
This has two main implications: in this type of supply chain, as in traditional supply chains, smoothing order still impact on supply chain performance; Information Exchange configuration outperforms the Traditional supply chain. The two implications are confirmed by the values of Fill Rate, which are generally higher $(84.2 \% ; 83.6 \%$; $80.9 \%$ ) and show the same "opposite trend" with respect to operational performance, as in traditional supply chain.

To sum up:

IV. Information exchange supply chain exhibits a linear increase of order variance upstream. Bullwhip, Inventory Instability and Intermittent Orders are not completely eliminated but reduced with respect to traditional supply chains. As in traditional supply chains, the magnitude of this noxious phenomenon is related to the order smoothing levels.

V. The smoothing parameter variations impact the performance of the supply chain with slightly reduced magnitude as compared to the Traditional configuration. Customer service level shows the same "opposite trend" with respect to operational performance for increasing smoothing parameters, as in traditional supply chains, but with weaker intensity.

VI. Information Exchange generally outperforms the Traditional configuration. Ceteris paribus, all performance measures are superior to traditional.

VII. Proportional controller tuning remains crucial for supply chain performance in information exchange.

\subsection{Synchronised Supply}

Results indicate that proportional controller tuning in Synchronised Supply configuration weakly impacts on supply chain performance. Synchronised supply chain outperforms the previous scenarios, both in terms of operational performance and customer service level. A remarkable performance improvement is observed, regardless the proportional controller setting. The results reassert the empirical studies of Holweg et al. (2005) on synchronised supply chain performance: bullwhip is generally eliminated, inventory is always stabilised and intermittent demand is eliminated.

Order Variance Ratio values are significantly lower than in previous supply chain configurations. This metric reveals the amplification dampening property of synchronised supply chain: the shock in market demand causes a weak amplification of orders at the echelons $i=4$ and $i=3$, promptly smoothed at the highest nodes of the chain. Synchronised supply chain possesses the inventory stability transmission property: the Inventory Variance Ratio measure reveals a monotonous node-to-node reduction in upstream direction for all proportional controller designs. Furthermore, the Dejonckheere's et al. notation shows dramatic improvements in operational performance for all order smoothing designs, as inventory levels are noticeable reduced for all echelons.

Systemic Zero-Replenishment for the design $T_{y}=T_{w}=2 T_{p}$ and $T_{y}=T_{w}=T_{p}+1$ is equal to the optimal theoretical value and indicates the maximum operational responsiveness. Only design $T y=T_{w}=T_{p}$ shows a ZeroReplenishment value equal to 8 , corresponding to a reduction of lumpy orders of $92 \%$ and $90 \%$ with respect to Traditional and Information Exchange.

Besides, Average Fill rate reveals the stability property of Synchronised for variations of proportional controllers in terms of customer service level: the maximum difference in the three smoothing order levels is $1.7 \%$. Ceteris paribus, Average fill rate improves up to $9.4 \%\left(T_{y}=T_{w}=2 T_{p}\right.$ design $)$.

The radar areas of Proportional Controller Bullwhip Slope and Proportional Controller Inventory Instability Slope confirm the insensitivity of synchronised supply chain echelons to variations on smoothing levels.

The opposite trend of process and customer service metrics persists but the extent of the variation is relatively slight: the values of the metrics remain almost unaltered through variations of proportional controllers. This indicates the weak impact of parameter setting on supply chain performance with respect to the Information Exchange and Traditional Supply Chains, at least within the range studied.

The Synchronised Supply summaries the benefits of high collaboration: the Systemic Zero-Replenishment in two sets is equal to the optimal theoretical value and indicates the maximum operational responsiveness. High values of Average Fill Rate, low inventory levels and variance, and low order variance for all settings reflect the configuration's stability, robustness and scalability.

To sum up:

VIII. Bullwhip is generally avoided, inventory is always stabilised, and intermittent orders are eliminated for all order smoothing levels.

IX. Synchronised supply chain largely outperforms Traditional and Information Exchange supply chains.

$X$. The values of the metrics persist almost unaltered for different proportional controllers. The negative effect of order smoothing rate on customer service in almost absent.

XI. The smoothing parameter variations impact very weakly on the synchronised supply chain performance.

\section{RESULTS}

The main results of this work are:

(i) Supply Chain Collaboration impacts more than order smoothing on overall supply chain performance. 
Both Collaboration and smoothing order have significantly impact on supply chain performance. Order smoothing mitigates bullwhip effect and limits inventory variability and lumpy orders; however, as showed in literature and reconfirmed in this work, it may have negative impact on customer service. As order smoothing increases, the supply chain operational performance improves but the customer service level worsens. Smoothing the order rate can be considered a "sedative" of bullwhip effect. Despite the potential loss of customer service, both in traditional and information exchange supply chains order smoothing is an effective approach against bullwhip effect. Supply Chain Collaboration eliminates bullwhip effect, provides inventory stability and enhanced customer service level. For an increasing collaboration degree (in traditional to synchronised supply chains) the overall supply chain performance improves. Particularly, synchronised supply chain allows the elimination of inefficiencies by linking the inventory and replenishment decision, and a reduction of inventory levels. It is likely to consider Supply Chain Collaboration the bullwhip avoidance technique par excellence: visibility is the solution.

(ii)The negative effect on customer service of smoothing order is almost eliminated in collaborative supply chain.

The "side effect" on customer service level, caused by increasing order smoothing in low collaborative supply chains, is avoided in synchronised supply chains. Furthermore, results support the former conclusion of this work on the impact of collaboration supply chain on operational performance and customer service level. The outcomes of this work are summarised in Figure 9.

\section{Figure 9. Impact of Supply Chain Collaboration and order smoothing on operational performance and customer service level}

\section{CONCLUSIONS}

The paper provided a structured assessment of the impact of collaboration and smoothing replenishment rules on supply chain operational performance and customer service level. The research objective were to assess the impact of collaboration and the smoothing order rules, and to show if the negative effect on customer service of smoothing order rate persists in collaborative supply chain structures.

To fulfil the research objectives three supply chain configurations, Traditional, Information Exchange and Synchronised (Holweg et al. 2005), in which orders are generated by smoothing $(S, R)$ policies are studied for different proportional controllers. A supply chain stress test was performed through a sudden and intense change in demand. The assessment system was based on two criteria, "operational performance" and "customer service level" and measured both local (single echelon) and systemic performance (supply chain). Supply chains were modelled through differential equations.

The main technical considerations on the three configurations are:

- Traditional supply chain

I. Traditional supply chain exhibits a geometrical increase of order variance in up-stream direction, high inventory variability and intermittent order phenomenon. The magnitude of these noxious phenomena is strongly related to the order smoothing levels.

II. As order smoothing increases, the supply chain operational performance improves (Inventory variance ratio, Average Inventory, Zero-Replenishment) but the customer service level worsens (Fill Rate). Smoothing the order rate noticeably limits the magnitude of bullwhip effect but it can result in poor customer service.

III. The smoothing parameter variations significantly impact on performance of traditional supply chains

- Information exchange supply chain.

IV. Information exchange supply chain exhibits a linear increase of order variance upstream. Bullwhip, Inventory Instability and Intermittent Orders are not completely eliminated but reduced with respect traditional supply chain. As in traditional supply chain, the magnitude of this noxious phenomenon is related to the order smoothing levels.

V. The variation on the smoothing parameter has a slight impact on the supply chain performance as compared to the Traditional configuration. Customer service level shows the same "opposite trend" with respect to operational performance for increasing smoothing parameters, as in traditional supply chain, but with weaker intensity.

VI. Information Exchange supply chains generally outperform the Traditional configuration. Ceteris paribus, all performance measures are superior to traditional.

VII. Proportional controller tuning remains crucial for supply chain performance in information exchange. - Synchronised supply chain

VIII. Bullwhip is generally eliminated, inventory is always stabilised, and intermittent orders are eliminated for all order smoothing levels.

IX. Synchronised supply chains largely outperform Traditional and Information Exchange supply chains.

$X$. The values of the metrics persist almost unaltered through variations of proportional controllers. The negative effect of order smoothing rate on customer service in almost absent. 
XI. The smoothing parameter variations impact very weakly on the synchronised supply chain performance.

As a summary, the main conclusions of this paper are:

(i) Supply Chain Collaboration affects overall supply chain performance more than order smoothing .

(ii) The negative effect on customer service of smoothing order is almost eliminated in collaborative supply chains.

The limitations of the present study also represent opportunities for further research in the bullwhip field. The impact of imprecise information, multiproduct scenarios, variable manufacturing lead time, capacitated raw material supply condition, and stochastic demand on synchronised supply chain need additional research.

\section{ACKNOWLEDGMENT}

The authors wish to thank professor José M. Framiñán and the anonymous referees for insightful comments on earlier versions of the paper. This research was accomplished while the authors were with the University of Seville (Spain) and Cardiff University (UK) as visiting $\mathrm{PhD}$ students, funded by the Italian Ministry of University and Research.

\section{Appendix 1}

\section{Nomenclature}

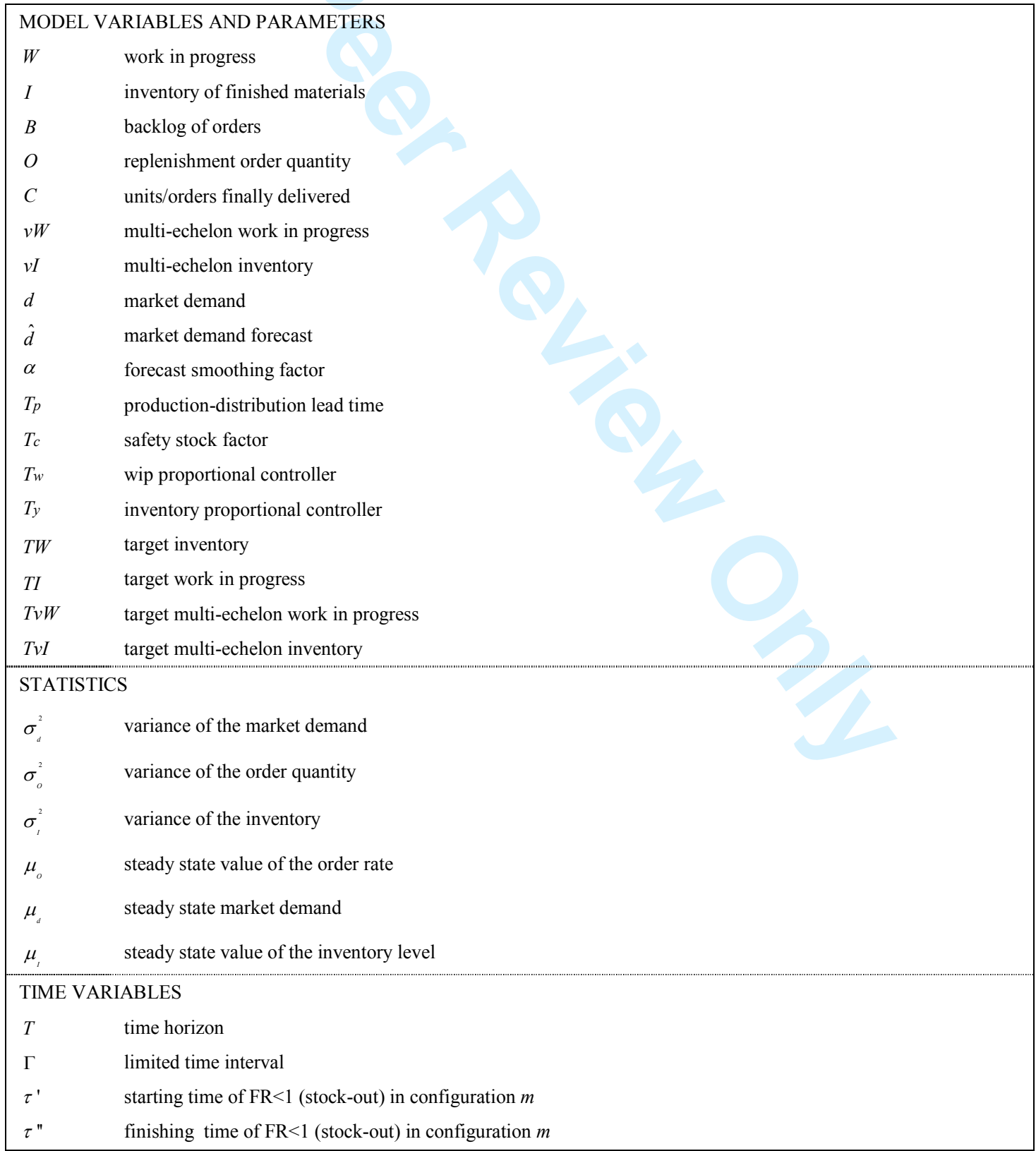




\begin{tabular}{|ll|}
\hline$\tilde{\tau}^{\prime}$ & starting time of $\mathrm{FR}<1$ in the worst case \\
$\tilde{\tau}^{\prime \prime}$ & finishing time of $\mathrm{FR}<1$ in the worst case \\
\hline INDEXES & \\
$i$ & echelon's position in the supply chain \\
$K$ & total number of echelons \\
$n$ & level of order smoothing \\
$N$ & supply chain configuration \\
$m$ & total number of configurations \\
$M$ & generic simulation \\
\hline & total number of simulations \\
\hline
\end{tabular}

\section{Appendix 2}

\section{The weight of Proportional Controller tuning: water tank model and trade-off analysis.}

Suggested by Holweg et al. (2005), the impact of proportional controller tuning is herein described through a hydraulic similarity. In the water tank analogy, water represents inventory, flows represent item distribution rates along the chain, valves represent the ordering decision. The regulation of the valve depends from the decision parameters of the order rule and from demand and lead times.

For a smoothing $(S, R)$ policy, these decision parameters are the safety stock factor, the demand forecasting coefficient and the proportional controller. For fixed safety stock factor and demand forecasting coefficient, the proportional controller tuning is the unique regulator of the valve.

In a hydraulic system, an imminent alteration of the flow rate can generate a phenomenon known as "water hammer" (Allevi 1902), a threatening shockwave propagating in the pipeline. A water hammer can cause the conduit to break if the pressure of the fluid is high enough. The remedy to the water hammer consists in reducing the fluid pressure. One possibility is to install a shock absorber, a hydro-pneumatic device designed to smooth out or damp shock impulses and dissipate kinetic energy. Water pressure can also be reduced diminishing the flow rate by tuning a valve. In the water tank analogy, the water hammer phenomenon can symbolise bullwhip, the shockwave symbolises the information distortion, the shock absorber symbolises the safety stock, and the regulation of the valve represents proportional controller tuning.

In supply chain large safety stocks enable production inventory system to absorb market-related shocks and assure a high customer service level (Graves and Willems 2003, Disney et al. 2006), but implies massive holding costs (Hax and Candea 1984). Large safety stock can only offer a costly ex post pseudo-remedy to increasing demand when bullwhip is already spreading along the chain. On the contrary, proportional controllers, like the pressure regulating valve for the water hammer phenomenon, prevent the phenomenon limiting the potential propagation of the bullwhip shockwave along the chain. As safety stock, proportional controllers reveals has its drawback. In a hydraulic system, reducing excessively the flow rate can impede to reach in time the desired fluid level; analogously, in a supply chain, an exaggerate order rate smoothing can cause the customer service level to degenerate. The proportional controller tuning has to be based on a robust and context-related trade-off analysis between operational cost saving and backlog costs, especially in no-collaborative supply chains. "The order-upto policy can be tuned to suit a variety of objectives. The one that will be the best in a given situation will depend on a number of factors" (Disney et al. 2006).

\section{Appendix 3}

\section{The different decision level in adopting bullwhip solving approach: tactical and strategic dimensions}

The adoption of a bullwhip technique is evidently concerned with managerial decisions. Within Anthony's (1965) planning and control decision framework, proportional controller tuning of the $(S, R)$ can be considered a tactical decision, while the adoption of a supply chain collaboration practice falls under the category of strategic decisions. Paraphrasing Anthony, the proportional controller tuning is embedded in the process by which managers assure that resource are used effectively and efficiently in the accomplishment of the organisation's objective in a medium range time horizon. On the other hand, the adoption of a supply chain collaboration practice is part of the process of deciding on the objectives of the organisation, on changes in these objectives, on the policies used to attain these objectives.

In traditional and information exchange supply chains, smoothing the order rate noticeable limits the magnitude of bullwhip effect but can result in poor customer service level. These result highlight that, as showed in literature (Dejonckheere et al. 2003, Disney et al. 2006, Disney et al. 2007, Disney and Lambrecht 2008) in low collaborative supply chains the proportional controller tuning has to be based on a robust and context-related trade-off analysis between operational cost saving and backlog/lost sales costs. In traditional and information 
exchange supply chains, the risk related to tactical decision making on the degree of smoothing order is relevant. This risk is undoubtedly lowered in synchronised supply chain, where smoothing parameter variations very weakly impact on performance

Synchronised supply chain eliminates bullwhip, provides inventory stability and enhanced customer service level: it avoids every plague in Pandora's industrial box (Holweg et al. 2005). It would seem intuitive that all companies should implement supply chain synchronisation practices. In the real business world, realising supply chain collaboration means adopting a Large Scale Supply Chain collaboration project. This kind of solutions, by their very nature, imposes its own logic on a company's strategy, organization and culture. It is recognised that the enormous technical challenge of implementing collaboration practices requires large investments of money, time, and expertise (Davenport, 1998). Furthermore, several factors need to be considered before beginning efforts towards synchronising the supply chain, e.g. geographical, demand-related, product-related (Holweg et al. 2005). A further element to be thoroughly considered is the investment pay-off: "if you're not careful, the dream of information integration can turn into a nightmare" (Davenport 1998). The frustration with the lack of financial return on supply chain collaboration effort (Holweg et al. 2005) can degenerate into "horror stories" about failed or out-of-control projects (Davenport 1998). Although in this work the obstacles in implementing collaboration practice are not issued, the previous considerations highlight the need for a structured and careful ex ante estimation of collaboration hazards and benefits (Shang and Seddon 2002).

\section{REFERENCES}

Agrawal, S., Sengupta, R.N., and Shanker, K., 2009. Impact of information sharing and lead time on bullwhip effect and onhand inventory. European Journal of Operational Research, 192 (2), 576-593.

Allevi, L., 1902. Teoria generale del moto perturbato dell'acqua nei tubi in pressione (colpo d'ariete). Annali della Società degli Ingegneri ed Architetti Italiani, 17(5), 285-325.

Andraski, J.C., 1994. Foundations for a successful continuous replenishment programme. International Journal of Logistics Management, 5 (1), 1-8.

Anthony, R.N., 1965. Planning and control systems: a framework for analysis. Cambridge: Harvard University.

Axsäter, S., 1985. Control theory concepts in production and inventory control. International Journal of Systems Science, 16 (2), 161-169.

Aggelogiannaki, E., Doganis, P., and Sarimveis, H., 2008. An adaptive model predictive control configuration for production-inventory systems. International Journal of Production Economics, 114 (1), 165-178.

Bagchi, P.K., 1996. Role of benchmarking as a competitive strategy: the logistics experience. International Journal of Physical Distribution and Logistics Management, 26 (2), 4-22.

Bailey, K., and Evans, B., 2006. Understanding the nature of collaboration within fresh produce value chains. Cardiff Logistics \& Operations Management Working Papers, L06/001, 1-8.

Barrat, M., 2004. Understanding the meaning of collaboration in the supply chain. Supply Chain Management, 9 (1), 30-42.

Beamon, B.M., 1999. Measuring supply chain performance, International Journal of Operations and Production Management, 19 (3), 275-292.

Beamon, B.M., and Chen, V.C.P., 2001. Performance analysis of conjoined supply chains. International Journal of Production Research, 39 (14), 3195-3218.

Boute, R.N., et al., 2007. Designing replenishment rules in a two-echelon supply chain with a flexible or an inflexible capacity strategy. International Journal of Production Economics, 119 (1), 187-198.

Boute, R.N., et al., 2009. An integrated production and inventory model to dampen upstream demand variability in the supply chain. European Journal of Operational Research, 178 (1), 121-142.

Byrne, P.J., and Heavey, C., 2006. The impact of information sharing and forecasting in capacitated industrial supply chains: A case study. International Journal of Production Economics, 103 (1), 420-437.

Cachon, G., and Fisher, M., 1997. Campbell soup's continuous replenishment program: Evaluation and enhanced inventory decision rules. Production and Operations Management, 6 (3), 266-276.

Cachon, G., and Fisher, M., 2000. Supply chain inventory management and the value of shared information. Management Science, 46 (8), 1032-1048.

Cannella, S., and Ciancimino, E., 2008. The APIOBPCS Deziel and Eilon parameter configuration in supply chain under progressive information sharing strategies. In Proceedings Winter Simulation Conference, art. no. 4736385, 2682-2690.

Cannella, S., Ciancimino, E., and Márquez, A.C., 2008. Capacity constrained supply chains: A simulation study. International Journal of Simulation and Process Modelling, 4 (2), 139-147.

Chandra, C., and Grabis, J., 2005. Application of multi-steps forecasting for restraining the bullwhip effect and improving inventory performance under autoregressive demand. European Journal of Operational Research, 166 (2), 337-350.

Chatfield, D.C., et al., 2004. The bullwhip effect - Impact of stochastic lead time, information quality, and information sharing: A simulation study. Production and Operations Management, 13 (4), 340-353.

Chatfield, D.C., and Hayya, J.C., 2007. All-zero forecasts for lumpy demand: A factorial study. International Journal of Production Research 45 (4), 935-950.

Chen, Y.F, et al., 2000. Quantifying the bullwhip effect in a simple supply chain: the impact of forecasting, lead times, and information. Management Science, 46 (3), 436-443.

Chen, Y.F, and Disney, S.M., 2007. The myopic Order-Up-To policy with a proportional feedback controller. International Journal of Production Research, 45 (2), 351-368.

Ciancimino. E., and Cannella, S., 2009. Modelling the bullwhip effect dampening practices in a limited capacity production network. Lecture Notes in Business Information Processing 20, 475-486.

Clark, A.J., and Scarf, H., 1960. Optimal Policies for a Multi-Echelon Inventory Problem. Management Science, 6 (4), $475-$ 490. 
Coyle, R.G., 1977. Management System Dynamics. New York: John Wiley \& Sons.

Croston, J.D., 1972. Forecasting and stock control for intermittent demands. Operational Research Quarterly, 23 (3), 289 303

Davenport, T.H., 1998. Putting the enterprise into the enterprise system. Harvard business review, 76 (4), 121-131.

DeCroix, G.A., 2006. Optimal policy for a multiechelon inventory system with remanufacturing. Operations Research 54 (3), 532-543.

Dejonckheere, J., et al., 2003. Measuring and avoiding the bullwhip effect: A control theoretic approach. European Journal of Operational Research, 147 (3), 567-590.

Dejonckheere, J., et al., 2004. The impact of information enrichment on the Bullwhip effect in supply chains: A control engineering perspective. European Journal of Operational Research, 153 (3), 727-750.

De Kok, T., et al, 2005. Philips electronics synchronizes its supply chain to end the bullwhip effect. Interfaces, 35 (1), 37-48.

De Toni, A., Tonchia, S., 2001. Performance measurement systems: Models, characteristics and measures. International Journal of Operations and Production Management, 21 (1-2), 46-70.

Deziel, D.P., and Eilon, S., 1967. A linear production-inventory control rule. The Production Engineer, 43, 93-104.

Disney, S.M., Naim, M.M., Towill, D.R., 1997. Dynamic simulation modelling for lean logistics. International Journal of Physical Distribution and Logistics Management 27 (3), 174-196.

Disney, S.M., Holmström, J., Kaipia, R., Towill, D.R., 2001.Implementation of a VMI production and distribution control system. In: Proceedings of International Symposium of Logistics. Salzburg, Austria.

Disney, S.M., and Towill, D.R., 2002. A discrete transfer function model to determine the dynamic stability of a vendor managed inventory supply chain. International Journal of Production Research, 40 (1), 179-204.

Disney, S.M., and Towill, D.R., 2003a. On the bullwhip and inventory variance produced by an ordering policy. Omega, the International Journal of Management Science, 31 (3), 157-167.

Disney, S.M., and Towill, D.R., 2003b. The effect of vendor managed inventory (VMI) dynamics on the Bullwhip Effect in supply chains. International Journal of Production Economics, 85 (2), 199-215.

Disney, S.M., and Towill, D.R., 2003c. Vendor-managed inventory and bullwhip reduction in a two-level supply chain. International Journal of Operations and Production Management, 23 (5-6), 625-651

Disney, S.M., and Grubbström, R.W., 2004. Economic consequences of a production and inventory control policy. International Journal of Production Research, 42 (17), 3419-3431.

Disney, S.M., Naim, M.M., and Potter, A., 2004a. Assessing the impact of e-business on supply chain dynamics. International Journal of Production Economics, 89 (2), 109-118.

Disney, S.M., Towill, D.R., and Van De Velde, W., 2004b. Variance amplification and the golden ratio in production and inventory control. International Journal of Production Economics, 90 (3), 295-309.

Disney, S.M, and Towill, D.R., 2006. A methodology for benchmarking replenishment-induced bullwhip. Supply Chain Management, 11 (2), 160-168.

Disney, S.M., et al., 2006. Taming the bullwhip effect whilst watching customer service in a single supply chain echelon. European Journal of Operational Research, 173 (1), 151-172.

Disney, S.M., et al., 2007. Controlling bullwhip and inventory variability with the golden smoothing rule. European Journal of Industrial Engineering 1 (3), 241-265.

Disney, S.M., et al., 2008. The value of coordination in a two-echelon supply chain. IIE Transaction, 40 (3), 341-355.

Disney, S.M, and Lambrecht, M.R., 2008. On Replenishment Rules, Forecasting, and the Bullwhip Effect in Supply Chains. Foundations and Trends in Technology, Information and Operations Management, 2 (1), 1-80.

Dong, L., and Lee, H.L., 2003. Optimal policies and approximations for a serial multiechelon inventory system with timecorrelated demand. Operations Research, 51 (6), 969-980

Forrester, J., 1961. Industrial Dynamics. Cambridge: MIT Press.

Geary, S., Disney, S.M., and Towill, D.R., 2006. On bullwhip in supply chains - Historical review, present practice and expected future impact. International Journal of Production Economics, 101 (1), 2-18.

Gonçalves, P., Hines, J., and Sterman, J., 2005. The impact of endogenous demand on push-pull production system. System Dynamics Review, 21 (3), 187-216.

Graves, S.C., Willems, S.P., 2003. Supply chain design: Safety stock placement and supply chain configuration. In: de Kok, A.G., Graves, S.C. (Eds.), Handbooks in OR \& MS, vol. 11. Elsevier: Amsterdam, 95-132.

Gunasekaran, A., Patel, C., and Tirtiroglu, E., 2001. Performance measures and metrics in a supply chain environment. International Journal of Operations and Production Management, 21 (1-2), 71-87.

Gunasekaran, A., and Kobu, B., 2007. Performance measures and metrics in logistics and supply chain management: A review of recent literature (1995-2004) for research and applications. International Journal of Production Research, 45 (12), 2819-2840.

Hammond, J.H., 1994. Barilla SpA (A). Harvard Business School Case 694-046.

Hausman, W.H., 2003. Supply chain performance metrics. In: Harrison, T.P., Lee, H.L., and Neale, J.J, eds. The practice of supply chain management: where theory and practice converge. Boston: Kluwer Academic Publishing, 61-73.

Hax, A.C., and Candea, D., 1984. Production and Inventory Management. Englewood Cliffs: Prentice-Hall.

Holmström, J., et al., 2002. Collaborative planning forecasting and replenishment: New solutions needed for mass collaboration. Supply Chain Management, 7 (3), 136-145.

Holt, C.C., et al., 1960. Planning Production, Inventories and Work Force. Englewood Cliffs: Prentice-Hall.

Holweg, M., et al., 2005. Supply chain collaboration: making sense of the strategy continuum. European Management Journal, 23 (2), 170-181.

Holweg, M., and Disney S.M., 2005. The Evolving Frontiers of the Bullwhip Problem. In EUROMA Conference Proceedings. Budapest, Hungary, 19-22 June, 707-716.

Hong-Minh, S.M., Disney, S.M., and Naim, M.M., 2000. The dynamics of emergency transhipment supply chains. International Journal of Physical Distribution and Logistics Management 30 (9), 788-815.

Hosoda, T., and Disney, S. M., 2006. The governing dynamics of supply chains: The impact of altruistic behaviour. Automatica, 42 (8), 1301-1309. 
Hosoda, T., et al., 2008. Is there a benefit to sharing market sales information? Linking theory and practice. Computers and Industrial Engineering, 54 (2), 315-326.

Hunter, N.A, 1990. Quick Response in Apparel Manufacturing. A Survey of the American Scene. Manchester: The Textile Institute.

Jakšič, M., and Rusjan, B., 2008. The effect of replenishment policies on the bullwhip effect: a transfer function approach. European Journal of Operational Research, 184 (3), 946-961.

John, S., Naim, M.M., and Towill, D.R., 1994. Dynamic analysis of a WIP compensated decision support system. International Journal of Management Systems Design, 1 (4), 283-297.

Kelepouris, T., Miliotis, P., Pramatari K., 2008. The impact of replenishment parameters and information sharing on the Bullwhip effect: a computational study. Computers and Operations Research, 35 (11), 3657-3670.

Kim, I., and Springer, M. 2008. Measuring endogenous supply chain volatility: Beyond the bullwhip effect. European Journal of Operational Research, 189 (1), 172-193.

Kim, J.G., et al., 2006. Quantifying the bullwhip effect in a supply chain with stochastic lead time. European Journal of Operational Research, 173 (2), 617-636.

Kleijnen, J.P.C., and Smits, M.T., 2003. Performance metrics in supply chain management. Journal of the Operational Research Society, 54 (5), 507-514.

Lalwani, C.S., Disney, S.M., and Towill, D.R., 2006. Controllable, observable and stable state space representations of a generalized order-up-to policy. International Journal of Production Economics, 101 (1), 172-184.

Lee, H.L., Padmanabhan, V., and Whang, S., 1997. Information distortion in a supply chain: the bullwhip effect. Management Science, 43 (4), 546-558.

Lee, H.L, and Whang, S., 2003. e-Business and Supply Chain Integration. In: Harrison, T.P., Lee, H.L., and Neale, J.J, eds. The practice of supply chain management: where theory and practice converge. Boston: Kluwer Academic Publishing, 123-128.

Lee, H.L., 2004. The Triple-A Supply Chain. Harvard Business Review, 82 (10), 102-112.

Magee, J.F. 1958. Production Planning and Inventory Control. New York: McGraw-Hill.

Makridakis, S., et al., 1982. The accuracy of extrapolation (time series) methods: Results of a forecasting competition. Journal of Forecasting, 1 (2), 111-153.

McKinsey \& Co., 1992. Evaluating the impact of alternative store formats. Chicago: Supermarket Industry Convention, Food Marketing Institute.

Naim, M.M., and Towill, D.R., 1995. What's in the pipeline? In Proceedings of the Second International Symposium on Logistics, Nottingham, UK, 11-12 July, 135-142.

Neely, A., Gregory, M., and Platts, K., 1995. Performance measurement system design: A literature review and research agenda. International Journal of Operations and Production Management, 15 (4), 80-116.

Ouyang, Y., 2007. The effect of information sharing on supply chain stability and the bullwhip effect. European Journal of Operational Research, 182 (3), 1107-1121

Reichhart, A., Framiñán, J.M., and Holweg, M., 2008. On the link between inventory and responsiveness in multi-product supply chains. International Journal of Systems Science, 39 (7), 677-688.

Riddalls, C.E., Bennett, S., and Tipi, N.S., 2000. Modelling the dynamics of supply chains. International Journal of Systems Science, 31 (8), 969-976.

Sahin, F., and Robinson Jr., E.P., 2005. Information sharing and coordination in make-to-order supply chains. Journal of Operations Management, 23 (6), 579-598.

Sarimveis, H., et al., 2008. Dynamic modeling and control of supply chain systems: A review. Computers and Operations Research, 35 (11), 3530-3561.

Schultz, C.R., 1987. Forecasting and inventory control for sporadic demand under periodic review. Journal of the Operational Research Society, 38 (5), 453-458.

Seifert, D., 2003. Collaborative planning, forecasting, and replenishment: how to create a supply chain advantage. New York: AMACOM.

Shang, J.S., Li, S., and Tadikamalla, P., 2004. Operational design of a supply chain system using the Taguchi method, response surface methodology, simulation, and optimization. International Journal of Production Research, 42 (18), 3823-3849.

Shang, S., and Seddon, P.B., 2000. Assessing and managing the benefits of enterprise systems: the business manager's perspective. Information Systems Journal, 12 (4), 271-299.

Silver, E.A., 1970. Some ideas related to the inventory control of items having erratic demand patterns. CORS J, 8 (2), 87 100.

Simatupang, T., and Sridharan, R., 2004. A benchmarking scheme for supply chain collaboration. Benchmarking: An International Journal, 11 (1), 9-30.

Simon, H.A., 1952. On the application of servomechanism theory to the study of production control, Econometrica, 20 (2), 247-268.

Sterman, J., 1989. Modeling managerial behavior: misperceptions of feedback in a dynamic decision making experiment. Management Science, 35(3), 321-339.

Swaminathan, J.M., and Tayur, S.R., 2003. Models for supply chains in e-Business. Management Science, 49 (10), 13871406.

Towill, D.R., 1982. Dynamic analysis of an inventory and order based production control system. International Journal of Production Research, 20(6), 671-687.

Towill, D.R., Zhou, L., and Disney, S.M., 2007. Reducing the bullwhip effect: Looking through the appropriate lens. International Journal of Production Economics, 108 (1-2), 444-453.

Vassian, H.F., 1955. Application of discrete variable servo theory to inventory control. Operations Research 3 (3), $272-282$.

VICS Merchandising Issue Committee, CPFR Committee, 1998. Collaborative Planning, Forecasting, and Replenishment Guidelines. Lawrenceville: Voluntary Interindustry Commerce Standards Associations.

Waller, M., Johnson, M.E., and Davis, T., 1999. Vendor-managed inventory in the retail supply chain. Journal of Business Logistics, 20 (1), 183-203. 
Warburton, R.D.H., 2004. An analytical investigation of the Bullwhip Effect. Production and Operations Management, 13 (2), 150-160.

Warburton, R.D.H., and Disney, S.M., 2007. Order and inventory variance amplifications: The equivalence of continuous and discrete time analyses. International Journal of Production Economics, 110 (1-2), 128-137.

Whang S., 1995. Coordination in operations: a taxonomy. Journal of Operations Management, 12 (3-4), 413-422.

Wright, D., and Yuan, X., 2008. Mitigating the bullwhip effect by ordering policies and forecasting methods. International Journal of Production Economics, 113 (2), 587-597.

Zipkin, P.H., 2000. Foundations of Inventory Management. New York: McGraw-Hill. 
Table 1. Conclusion on proportional controller and supply chain collaboration in the bullwhip avoidance phase

\begin{tabular}{|c|c|c|c|c|c|c|c|}
\hline & - METHODOLOGY & $\begin{array}{l}\cdot \text { ORDER } \\
\text { POLICY }\end{array}$ & $\begin{array}{l}\cdot \boldsymbol{P E R F O R M A N C E} \\
\text { METRICS }\end{array}$ & $\cdot \boldsymbol{\cdot}_{\text {STRUCTURES }}^{\text {MODL }}$ & - DEMAND PATTERN & • CONCLUSIONS ON ORDER SMOOTHING & • CONCLUSIONS ON COLLABORATION \\
\hline $\begin{array}{l}\text { Chen, Drezner, Ryan, } \\
\text { Simchi-Levi (2000) }\end{array}$ & - Statistical Methods & $\cdot(S, R)$ & $\begin{array}{l}\text { - Order Rate Variance } \\
\text { Ratio }\end{array}$ & $\begin{array}{l}\text { - Two supply chains } \\
\text {-Two-echelon } \\
\text { Traditional } \\
\text {-Multi-echelon Epos }\end{array}$ & - Auto regressive & & $\begin{array}{l}\text { - The difference between the variability in the centralised and decentralised } \\
\text { supply chains increases in upstream direction. } \\
\text { - With centralised information, he increase in variability at each stage is an } \\
\text { additive function of the lead time and the lead time squared, while for supply } \\
\text { chains without centrlalised information, the increase in variability at each } \\
\text { stage is at least multiplicative. }\end{array}$ \\
\hline Disney, Towill (2002) & - Discrete Time & $\begin{array}{l}:(S, R) \\
\text { - Smoothing }\end{array}$ & - Order Rate & $\begin{array}{l}\text { - Two-echelon VMI } \\
\text { supply chain }\end{array}$ & - Step & $\begin{array}{l}\text { - With matched proportional controllers (Deizel and Eilon } \\
\text { configuration) the system is stable. }\end{array}$ & $\begin{array}{l}\text { - Centralising customer demand information can significantly reduce the } \\
\text { bullwhip effect. }\end{array}$ \\
\hline $\begin{array}{l}\text { Dejonckheere, Disney, } \\
\text { Lambrecht, Towill } \\
(2003)\end{array}$ & $\begin{array}{l}\text { - Discrete Time } \\
\text { - Optimisation } \\
\text { Methods }\end{array}$ & $\begin{array}{l}:(S, R) \\
\text { - Smoothing }\end{array}$ & $\begin{array}{l}\text { - Order Rate Variance } \\
\text { Ratio }\end{array}$ & $\begin{array}{l}\text { - Traditional } \\
\text { Production-Inventory } \\
\text { System }\end{array}$ & $\begin{array}{l}\text { - Sinusoidal } \\
\text { - Real-life } \\
\text { - i.i.d. } \\
\text { - Step }\end{array}$ & $\begin{array}{l}\text { - The order smoothing parameter has a significant impact on } \\
\text { the bullwhip effect. } \\
\text { - (For step increase) for the smoothing policy, there is less } \\
\text { overshooting in orders compared to the order-up-to policy. } \\
\text { - (For step increase) inventory related costs will be larger for } \\
\text { the smoothing policy than for the order-up-to policy. } \\
\text { - The selection of forceast factors and proportional controller } \\
\text { implies a trade off between inventory holding and shortage } \\
\text { costs. }\end{array}$ & \\
\hline $\begin{array}{l}\text { Chatfield, Kim, } \\
\text { Harrison, Hayya (2004) }\end{array}$ & $\begin{array}{l}\text { - Object-Oriented } \\
\text { Simulation }\end{array}$ & $\cdot(S, R)$ & $\begin{array}{l}\text { - Order Rate Variance } \\
\text { Ratio }\end{array}$ & $\begin{array}{l}- \text { Two four-echelon } \\
\text { supply chains } \\
\text {-Traditional } \\
\text {-Epos }\end{array}$ & - i.i.d. & & $\begin{array}{l}\text { - Information sharing decelerates the bullwhip effect in upstrean direction. } \\
\text { Information sharing secanaros exhhibits a linear trend with hechelon, whereas } \\
\text { non-information sharing exhibits a quasi-exponential increase of order } \\
\text { variance amplificiation. } \\
\text { - Information sharing reduces total order variance amplification and node-to- } \\
\text { node variance amplification. }\end{array}$ \\
\hline $\begin{array}{l}\text { Dejonckheere, Disney, } \\
\text { Lambrecht, Towill } \\
(2004)\end{array}$ & $\begin{array}{l}\text { - Spreadsheet } \\
\text { Simulation } \\
\text { - Discrete Time }\end{array}$ & $\begin{array}{l}:(S, R) \\
\text { : Smoothing }\end{array}$ & $\begin{array}{l}\text { - Order Rate Variance } \\
\text { Ratio }\end{array}$ & $\begin{array}{l}- \text { Two four-echelon } \\
\text { supply chains } \\
\text {-Traditional } \\
\text {-Epos }\end{array}$ & - i.i.d. & $\begin{array}{l}\text { - The smoothing order-up-to policy mitigates the geometrical } \\
\text { increase of Order rate variance ratio along a traditional } \\
\text { supply chain. } \\
\text { - Information sharing and smoot }\end{array}$ & $\begin{array}{l}\text { - Sharing information dampens the bulllwhip trend from geometrical to linear } \\
\text { but does not eliminnate it when orders are regulated by a }(S, R) \text {. }\end{array}$ \\
\hline $\begin{array}{l}\text { Disney, Towill, Van de } \\
\text { Velde (2004b) }\end{array}$ & $\begin{array}{l}\text { - Discrete Time } \\
\text { - Optimisation } \\
\text { Methods }\end{array}$ & $\begin{array}{l}\text { : }(S, R) \\
\text { Smoothing }\end{array}$ & $\begin{array}{l}- \text { Order Rate Variance } \\
\text { Ratio } \\
\text { - Inventory Variance } \\
\text { Ratio }\end{array}$ & $\begin{array}{l}\text { - Traditional } \\
\text { Production-Inventory } \\
\text { System }\end{array}$ & - i.i.d. & $\begin{array}{l}\text { - Bullwhipi is monotonically increasing in the proportional } \\
\text { controllers in the Deizel and Eilon Configuration. } \\
\text { - It is possible to avoid the bullwhip effect via the proper } \\
\text { designo of the productuction and inventory control ssstem. }\end{array}$ & \\
\hline $\begin{array}{l}\text { Shang, Li, Tadikamalla } \\
\text { (2004) }\end{array}$ & $\begin{array}{l}\text { - Discrete Event } \\
\text { Simulation } \\
\text { - Taguchi Technique }\end{array}$ & $\cdot(S, R)$ & $\begin{array}{l}\text { - Ordering, setup, } \\
\text { backorder, and } \\
\text { transportation costs }\end{array}$ & $\begin{array}{l}- \text { Three three-layer } \\
\text { supply chains } \\
\text {-Traditional } \\
\text {-Epos } \\
\text {-VMI }\end{array}$ & - S-shaped & & - Integration of suppliers help cut cycle times and reduce inventories. \\
\hline Warburton (2004) & - Continuous Time & $\begin{array}{l}:(S, R) \\
: \text { Smoothing }\end{array}$ & $\begin{array}{l}\text { - Inventory Level } \\
\text { - Order Rate }\end{array}$ & $\begin{array}{l}\text { - Traditional } \\
\text { Production-Inventory } \\
\text { System }\end{array}$ & - Step & $\begin{array}{l}\text { - The WIP proportional controller can diminish the inventory } \\
\text { oscillations. } \\
\text { - Fine tuning the ordering policy can guarantee that the } \\
\text { inventory will return exponentially fast to the desired level, } \\
\text { while not generating an overshoot. }\end{array}$ & 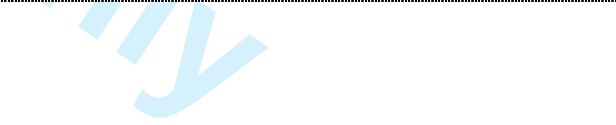 \\
\hline Byrne, Heavey (2006) & $\begin{array}{l}\text { - Discrete Event } \\
\text { Simulation }\end{array}$ & $\cdot(s, S)$ & $\begin{array}{l}- \text { Transportation, } \\
\text { ordering, production, } \\
\text { setup, inventory and } \\
\text { backorder costs }\end{array}$ & $\begin{array}{l}- \text { Two three-layer } \\
\text { supply chains } \\
\text {-Traditional } \\
\text {-Epos }\end{array}$ & - Real-life data set & & $\begin{array}{l}\text { - The use of improved information sharing techniques has a more significant } \\
\text { impact on the supply chain costs than the forecasting technique. }\end{array}$ \\
\hline $\begin{array}{l}\text { Disney, Farasyn, } \\
\text { Lambrecht, Towill, Van } \\
\text { de Velde (2006) }\end{array}$ & - Discrete Time & $\begin{array}{l}:(S, R) \\
\text { - Smoothing }\end{array}$ & $\begin{array}{l}\text { - Order Rate Variance } \\
\text { Ratio } \\
\text { - Inventory Variance } \\
\quad \text { Ratio } \\
\text { - Fill Rate }\end{array}$ & $\begin{array}{l}\text { - Traditional } \\
\text { Production-Inventory } \\
\text { System }\end{array}$ & $\begin{array}{l}\text { - i.i.d. } \\
\text { - Auto regressive and } \\
\text { moving average }\end{array}$ & $\begin{array}{l}\text { - Bullwhip avoidance, inventory reduction and customer } \\
\text { service level objectives can sometimes all be achieved } \\
\text { simultaneously. } \\
\text { - Dampening the bullwhip effect may have negative impact on } \\
\text { customer service. } \\
\text { - By tuning the order policy it is possible to exploit the }\end{array}$ & \\
\hline
\end{tabular}




\begin{tabular}{|c|c|c|c|c|c|c|c|}
\hline & & & & & & statistical properties of the demand process. & \\
\hline $\begin{array}{l}\text { Kim, Chatfield, } \\
\text { Harrison, Hayya (2006) }\end{array}$ & - Statistical Methods & $\cdot(S, R)$ & $\begin{array}{l}\text { - Order Rate Variance } \\
\text { Ratio }\end{array}$ & $\begin{array}{l}\text { - Two five-layer supply } \\
\text { chains } \\
\text {-Traditional } \\
- \text { Epos }\end{array}$ & $\cdot$ i.i.d. & & $\begin{array}{l}\text { - The bullwhip effect is attenuated from exponential to linear when } \\
\text { information is shared. }\end{array}$ \\
\hline Chen, Disney (2007) & $\begin{array}{l}\text { - Discrete Time } \\
\text { - Optimisation } \\
\text { Methods }\end{array}$ & $\begin{array}{l}:(S, R) \\
\text { Smoothing }\end{array}$ & $\begin{array}{l}\text { - Order Rate Variance } \\
\text { Ratio } \\
\text { - Inventory Variance } \\
\text { Ratio } \\
\text { - Holding and } \\
\text { shortage costs }\end{array}$ & $\begin{array}{l}\text { - Traditional } \\
\text { Production-Inventory } \\
\text { System }\end{array}$ & $\begin{array}{l}\text { - Auto regressive and } \\
\text { moving average }\end{array}$ & $\begin{array}{l}\text { - It is possible to reduce costs by tuning the inventory } \\
\text { proportional controller to the demand pattern. } \\
\text { - The proportional controller is able to reduce bullwhip by } 40 \% \\
\text { and realise economic savings of nearly } 20 \% \text {. }\end{array}$ & \\
\hline $\begin{array}{l}\text { Hosoda, Naim, Disney, } \\
\text { Potter (2008) }\end{array}$ & - Statistical Methods & $\cdot(S, R)$ & $\begin{array}{l}\text { - Standard Deviation } \\
\text { of the Prediction } \\
\text { - Errors }\end{array}$ & $\begin{array}{l}\text { - Two-echelon Epos } \\
\text { supply chain }\end{array}$ & - Real-life data set & & $\begin{array}{l}\text { - Sharing EPOS data reduces the second echelon's holding and backlog costs } \\
\text { by } 8-19 \% \text {. }\end{array}$ \\
\hline Jakšǐ̌, Rusjan (2008) & - Discrete Time & $\begin{array}{l}:(S, R) \\
\text { Smoothing }\end{array}$ & $\begin{array}{l}\text { - Order Rate Variance } \\
\text { Ratio }\end{array}$ & $\begin{array}{l}- \text { Two-echelon } \\
\text { Traditional supply } \\
\text { chains }\end{array}$ & - Sinusoidal & $\begin{array}{l}\text { - Choosing low inventory proportional controller value leads to } \\
\text { bullwhip effect elimination. }\end{array}$ & \\
\hline $\begin{array}{l}\text { Kelepouris, Miliotis, } \\
\text { Pramatari (2008) }\end{array}$ & $\begin{array}{l}\text { - Spreadsheet } \\
\text { Simulation }\end{array}$ & $\cdot(S, R)$ & $\begin{array}{l}\text { - Order Rate Variance } \\
\text { Ratio } \\
\text { - Fill Rate }\end{array}$ & $\begin{array}{l}- \text { - Two two-echelon } \\
\text { supply chains } \\
\text {-Traditional } \\
\text {-Epos }\end{array}$ & - Real-life data set & & $\begin{array}{l}\text { - Information sharing results in } 21 \% \text { order variability reduction, on average, } \\
\text { and in } 20 \% \text { mean cycle inventory reduction. }\end{array}$ \\
\hline Kim, Springer (2008) & - Continuous Time & - Smoothing & - Amplification ratio & $\begin{array}{l}\cdot \text { Two-echelon } \\
\text { Traditional supply } \\
\text { chain }\end{array}$ & - Step & $\begin{array}{l}\text { - The likelihood of strong cyclicality may be reduced by } \\
\text { increasing the wip proportional controller, or lowering } \\
\text { inventory proportional controller. }\end{array}$ & \\
\hline Wright, Yuan (2008) & - Continuous Time & - Smoothing & $\begin{array}{l}\text { - Order Rate Variance } \\
\text { Ratio } \\
\text { - Root Mean Square } \\
\text { - Holding, shortage } \\
\text { and purchase costs }\end{array}$ & $\begin{array}{l}\text { - Four-echelon } \\
\text { Traditional supply } \\
\text { chain }\end{array}$ & $\begin{array}{l}\text { - Local trends modified by } \\
\text { i.i.d. disturbances }\end{array}$ & $\begin{array}{l}\text { - A relatively low inventory proportional controller and a } \\
\text { slightly higher wip proportional controller provide stabaility } \\
\text { when combined with either Holt's or Brown's forcesasting } \\
\text { method. }\end{array}$ & \\
\hline $\begin{array}{l}\text { Agrawal, Sengupta, } \\
\text { Shaker (2009) }\end{array}$ & - Discrete Time & $\cdot(S, R)$ & $\begin{array}{l}\text { - Order Rate Variance } \\
\text { - Inventory Variance }\end{array}$ & $\begin{array}{l}\text { - Two two-stage supply } \\
\text { chains } \\
\text {-Traditional } \\
\text {-Epos }\end{array}$ & - Auto regressive & & $\begin{array}{l}\text { - Some part of bullwhip effect will always remain even after sharing both inter } \\
\text { as well as intra echelon information. }\end{array}$ \\
\hline $\begin{array}{l}\text { Boute, Disney, } \\
\text { Lambrecht, Van Houdt } \\
(2009)\end{array}$ & $\begin{array}{l}\text { : Discrete Time } \\
\text { Optimisation }\end{array}$ & $:(S, R)$ & $\begin{array}{l}- \text { Order Rate Variance } \\
\text { Ratio } \\
\text { - Holding, shortage } \\
\text { and capacity costs }\end{array}$ & $\begin{array}{l}- \text { Two-echelon } \\
\text { Traditional supply } \\
\text { chain }\end{array}$ & - i.i.d. & $\begin{array}{l}\text { - Dampening the order variability at the retailer may lead to } \\
\text { lower totat suppply chain costs. } \\
\text { - Order variance amplification increases total supply chain } \\
\text { costs, both in the flexible and inflexible capacity scenario. }\end{array}$ & \\
\hline
\end{tabular}


Figure 1. Flow of materials in the supply chains

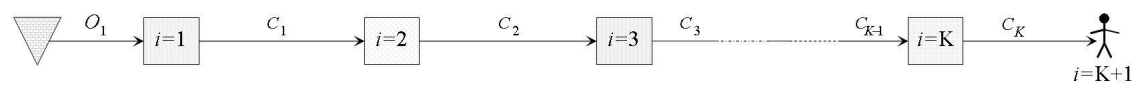

Figure 2. Traditional Supply Chain

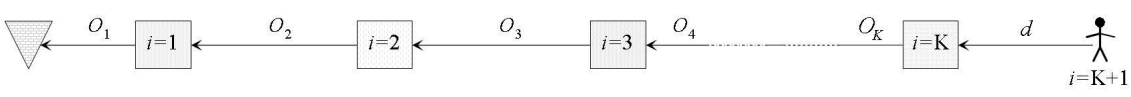

Figure 3. Information Exchange Supply Chain

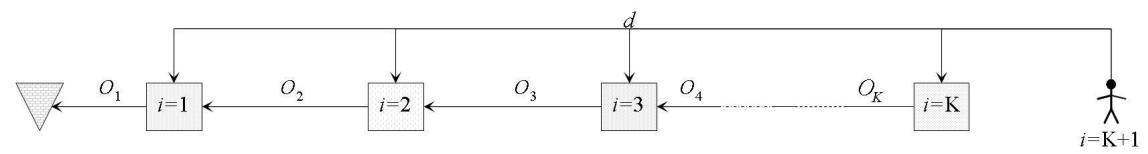

Figure 4. Synchronised Supply Chain

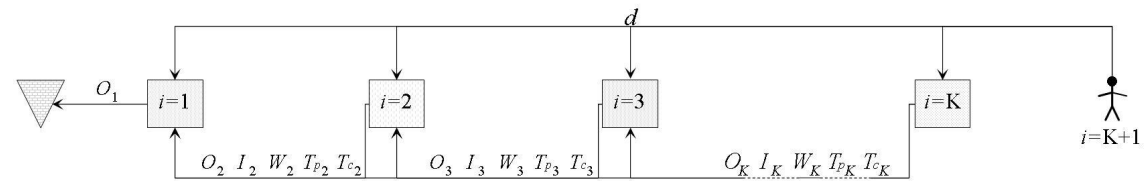

Table 2. Incoming data for a generic echelon $i$ in the different supply chain configurations

\begin{tabular}{clll}
\hline & $\begin{array}{l}\text { Traditional } \\
\text { Supply Chain }\end{array}$ & $\begin{array}{l}\text { Information } \\
\text { Exchange }\end{array}$ & $\begin{array}{l}\text { Synchronised } \\
\text { Supply Chain }\end{array}$ \\
\hline & & & - Order from subsequent echelon $O_{i+1}$ \\
incoming & - Order from & - Market demand $d$ \\
data & subsequent & echelon $O i+1$ & - Safety stock factors from all downstream echelons $T_{c_{i+1}} ; T_{c_{i+2} \ldots T_{c_{K}}}$ \\
& echelon $O i+1$ & - Market & - Lead times from all downstream echelons $T_{p_{i+1}} ; T_{p_{i+2} \ldots T_{p_{K}}}$ \\
& demand $d$ & - Inventory levels from all downstream echelons $I_{i+1}, I_{i+2} ; I_{K}$ \\
& & - Work in progress levels from all downstream echelons $W_{i+1}, W_{i+2} \ldots W_{K}$ \\
\hline
\end{tabular}

Table 3. Components of smoothing replenishment rules

smoothed inventory gap

difference between Target Inventory $T I_{i}$ and Inventory level $I_{i}$, divided by the Inventory proportional controller $T_{y_{i}}$. The Target

Inventory $T I_{i}$ is the product of the forecast on the order from the subsequent echelon $\hat{d}$ and the local safety stock factor $T_{c_{i}}$

smoothed wok in progress gap

difference between Target Work in Progress $T W_{i}$ and Work in Progress $W_{i}$, divided by the Work in Progress proportional controller

$T_{w_{i}}$. The Target Work in progress $T W_{i}$ is the product of the forecast on the order from the subsequent echelon $\hat{d}$ and the local lead

time $T_{p_{i}}$.

smoothed Multi-echelon inventory gap

difference between Target Multi-echelon Inventory $v T I_{i}$ and Multi-echelon Inventory level $v I_{i}$, divided by the Inventory proportional controller $T_{y_{i}}$. The Multi-echelon Inventory level $v I_{i}$ is the sum of the inventory levels $I_{j}$ from echelon $i$ to echelon $K$ (inventory level at echelon $i$ plus inventories levels of all downstream echelons $i+1 \ldots K)$. The Target Multi-echelon Inventory $v T I_{i}$ is the forecast on

market demand $\hat{d}_{K}$ multiplied by the sum of lead times $T_{p_{j}}$ from echelon $i$ to the echelon $K$ (sum of lead times $T_{p_{j}}$ from echelon $i$ to echelon $K$, it is the time period needed to deliver the finished product from the generic echelon $i$ to the final customer $K+1$ ).

smoothed Multi-echelon work in progress gap

difference between Target Multi-echelon Work in Progress $v T W_{i}$ and Multi-echelon Work in Progress $v W_{i}$, divided by the Work in Progress proportional controller $T_{w_{i}}$. The Multi-echelon Work in progress $v W_{i}$ is the sum of the Work in progress levels $W_{j}$ from echelon $i$ to echelon $K$ (work in progress at echelon $i$ plus work in progress of all downstream echelons $i+1 \ldots K$ ). The Target Multiechelon Work in progress $v W I_{i}$ is the forecast on market demand $\hat{d}_{k}$ multiplied by the sum of safety stocks $T_{c_{j}}$ from echelon $i$ to echelon $K$ (sum of safety stock factors $T_{c_{j}}$ from echelon $i$ to echelon $K$, it is the decision parameter set to cover the multi-echelon inventory at echelon $i$ ). 
Table 4. Equations

\begin{tabular}{|c|c|c|}
\hline Work in progress & $W_{i}(t)=W_{i}(t-1)+C_{i-1}(t)-C_{i-1}\left(t-T_{p_{i}}\right)$ & (4) \\
\hline Inventory & $I_{i}(t)=I_{i}(t-1)+C_{i-1}\left(t-T_{p_{i}}\right)-C_{i}(t)$ & $(5)$ \\
\hline Backlog & $B_{i}(t)=B_{i}(t-1)+O_{i+1}(t)-C_{i}(t)$ & $(6)$ \\
\hline Orders finally delivered $^{12}$. & $C_{i}(t)=\min \left\{O_{i+1}(t)+B_{i}(t-1) ; I_{i}(t-1)+C_{i}\left(t-T_{p_{i}}\right)\right\}$ & $(7)$ \\
\hline \multirow{2}{*}{ Demand forecast ${ }^{13}$} & $\hat{d}_{i}(t)=\alpha O_{i+1}(t-1)+(1-\alpha) \hat{d}_{i}(t-1)$ & $(8)$ \\
\hline & $O_{K+1}(t)=d(t)$ & (9) \\
\hline Non-negativity condition of order quantity & $O_{i}(t) \geq 0$ & $(10)$ \\
\hline Uncapacitated raw material supply condition $^{14}$ & $C_{i-1}(t)=O_{1}(t) ; \quad i=1$ & (11) \\
\hline Target Work in Progress & $T W_{i}(t)=T_{p_{i}} \hat{d}_{i}(t)$ & (12) \\
\hline Target Inventory & $T I_{i}(t)=T_{c_{i}} \hat{d}_{i}(t)$ & (13) \\
\hline Multi-echelon Work in progress & $v W_{i}(t)=\sum_{j=i}^{K} W_{j}(t)$ & (14) \\
\hline Multi-echelon Inventory & $v I_{i}(t)=\sum_{j=i}^{K} I_{j}(t)$ & (15) \\
\hline Target Multi-echelon Work in progress & $T v W_{i}(t)=\hat{d}_{K}(t) \sum_{j=i}^{K} T p_{j}$ & (16) \\
\hline Target Multi-echelon Inventory & $T v I_{i}(t)=\hat{d}_{K}(t) \sum_{j=i}^{K} T_{c_{j}}$ & $(17)$ \\
\hline Order quantity for Traditional Supply Chain & $O_{i}(t)=\hat{d}_{i}(t)+\frac{1}{T w_{i}}\left(T W_{i}(t)-W_{i}(t)\right)+\frac{1}{T y_{i}}\left(T I_{i}(t)-I_{i}(t)\right)$ & $(1)$ \\
\hline $\begin{array}{l}\text { Order quantity for Information Exchange Supply } \\
\text { Chain }\end{array}$ & $O_{i}(t)=\hat{d}_{\kappa}(t)+\frac{1}{T_{w_{i}}}\left(T W_{i}(t)-W_{i}(t)\right)+\frac{1}{T y_{i}}\left(T I_{i}(t)-I_{i}(t)\right)$ & $(2)$ \\
\hline Order quantity for Synchronised Supply Chain & $O_{i}(t)=\hat{d}_{\kappa}(t)+\frac{1}{T w_{i}}\left(T v W_{i}(t)-v W_{i}(t)\right)+\frac{1}{T y_{i}}\left(T v I_{i}(t)-v I_{i}\right.$ & ) (3) \\
\hline
\end{tabular}

Table 5. Supply Chain Configurations and related Equation System

\begin{tabular}{ll}
\hline Configuration & Equation \\
Traditional Supply Chain & $(1),(4),(5),(6),(7),(8),(9),(10),(11),(12),(13)$ \\
Information Exchange & $(2),(4),(5),(6),(7),(8),(9),(10),(11),(12),(13)$ \\
Synchronised Supply & $(3),(4),(5),(6),(7),(8),(9),(10),(11),(14),(15),(16),(17)$ \\
\hline
\end{tabular}

\footnotetext{
${ }^{12}$ Equation (7) models two conditions: backlog allowing and non-negative inventory. Orders no fulfilled in time are backlogged so that inventory remains a positive or null value.

${ }^{13}$ Demand is forecasted by simple exponential smoothing, a good choice for one-period-ahead forecasting (Disney and Lambrecht 2008). Exponential smoothing resulted to be the preferred technique among several methods in the over-cited Makridakis et al. (1982) article.

${ }^{14}$ Infinite raw material availability is assumed as in Beamon and Chen 2001. Orders from echelon $i=1$ are always entirely fulfilled.
} 
Table 6 Measurement System

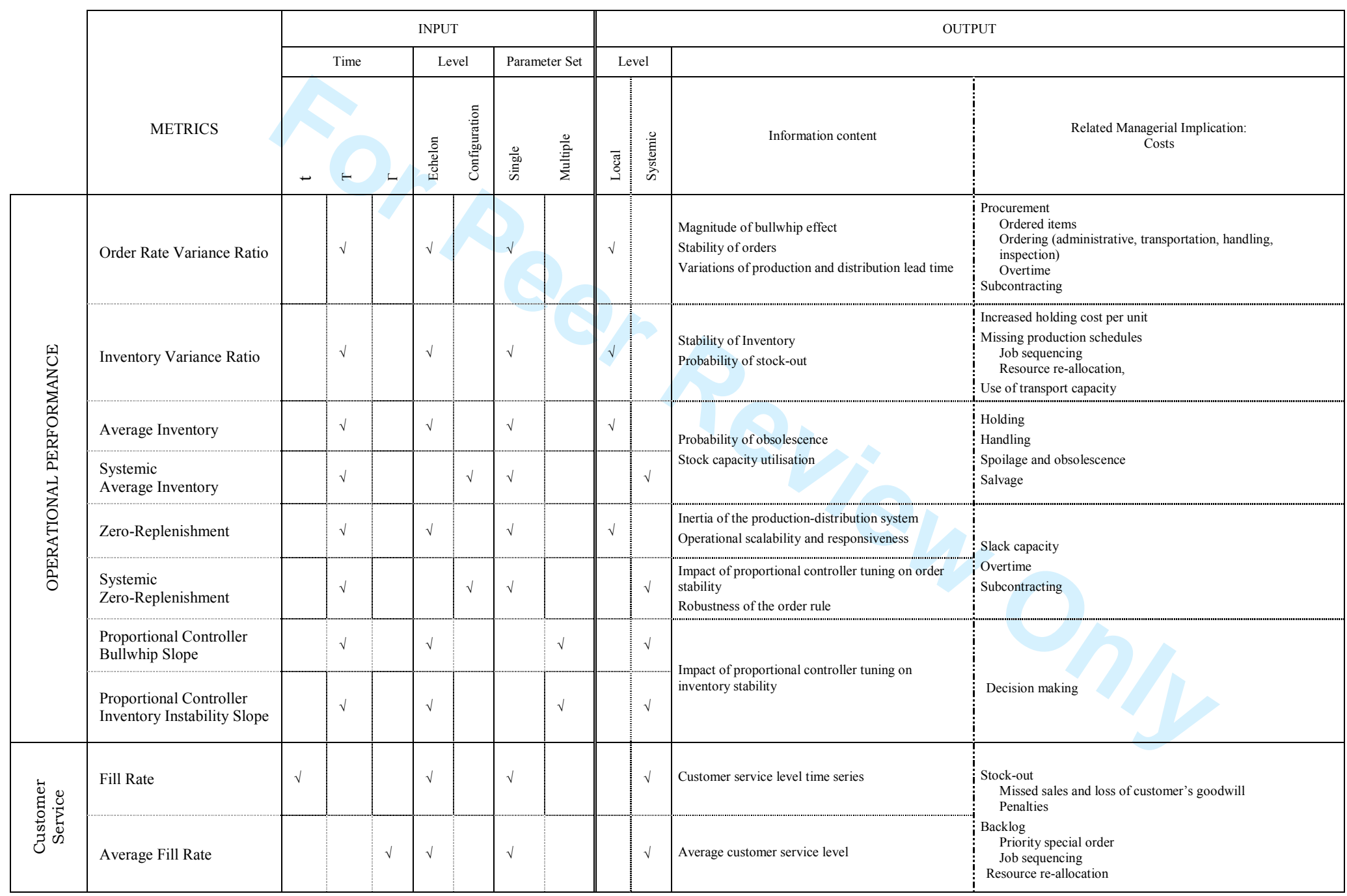


1

2

3

4

5

6

7

8

9

10

11

12

13

14

15

16

17

18

19

20

21

22

23

Table 7. Indexes

\begin{tabular}{|c|c|c|}
\hline $\begin{array}{l}\text { Supply Chain } \\
\text { Configuration }\end{array}$ & $m=1, \ldots M$ & The index $m$ stands for the supply chain configuration \\
\hline Echelon & $i=1, \ldots K$ & $\begin{array}{l}\text { The index } i \text { is representative of the echelon's position in the network. The echelon } i=1 \\
\text { stands for the manufacturer and } i=\mathrm{K}+1 \text { for the final customer }\end{array}$ \\
\hline Set & $n=1, \ldots N$ & The index $n$ identifies the level of order smoothing \\
\hline Simulation & $\omega=1, \ldots \Omega$ & The index $\omega$ identifies the generic simulation. The total number of simulations is $\Omega=M^{*} N$ \\
\hline
\end{tabular}

Table 8. Order Rate Variance Ratio

Order Rate Variance Ratio

\begin{tabular}{|c|c|c|c|c|c|c|c|c|c|}
\hline \multirow[b]{2}{*}{ Ech } & \multicolumn{3}{|c|}{$\mathrm{T}_{\mathrm{y}}=\mathrm{T}_{\mathrm{w}}=2$} & \multicolumn{3}{|c|}{$\mathrm{T}_{\mathrm{y}}=\mathrm{T}_{\mathrm{w}}=3$} & \multicolumn{3}{|c|}{$\mathrm{T}_{\mathrm{y}}=\mathrm{T}_{\mathrm{w}}=4$} \\
\hline & Trad & Info & Sync & Trad & Info & Sync & Trad & Info & Sync \\
\hline 4 & 17.00 & 16.44 & 10.90 & 9.52 & 8.72 & 4.94 & 5.74 & 5.28 & 3.06 \\
\hline 3 & 113.42 & 70.01 & 24.38 & 48.00 & 27.03 & 11.21 & 27.36 & 13.08 & 6.65 \\
\hline 2 & 290.76 & 145.36 & 24.08 & 129.12 & 40.45 & 12.50 & 63.22 & 17.00 & 8.05 \\
\hline 1 & 344.56 & 145.27 & 10.80 & 169.86 & 36.59 & 7.76 & 91.86 & 15.53 & 6.17 \\
\hline
\end{tabular}

Table 9. Inventory Variance Ratio

Inventory Variance Ratio

\begin{tabular}{|c|c|c|c|c|c|c|c|c|c|}
\hline \multirow[b]{2}{*}{ Ech } & \multicolumn{3}{|c|}{$\mathrm{T}_{\mathrm{y}}=\mathrm{T}_{\mathrm{w}}=2$} & \multicolumn{3}{|c|}{$\mathrm{T}_{\mathrm{y}}=\mathrm{T}_{\mathrm{w}}=3$} & \multicolumn{3}{|c|}{$\mathrm{T}_{\mathrm{y}}=\mathrm{T}_{\mathrm{w}}=4$} \\
\hline & Trad & $\operatorname{Inf}$ & Sync & Trad & $\operatorname{Inf}$ & Sync & Trad & $\operatorname{Inf}$ & Sync \\
\hline 4 & 46.90 & 43.91 & 23.67 & 30.25 & 31.67 & 21.39 & 29.37 & 33.20 & 20.17 \\
\hline 3 & 312.86 & 194.08 & 16.06 & 145.47 & 55.03 & 15.94 & 66.60 & 29.55 & 15.90 \\
\hline 2 & 451.54 & 177.82 & 14.51 & 248.74 & 58.61 & 13.84 & 164.53 & 26.94 & 13.67 \\
\hline 1 & 258.15 & 52.61 & 12.75 & 161.68 & 44.75 & 12.48 & 128.94 & 32.08 & 12.22 \\
\hline
\end{tabular}

Figure 5. Proportional Controller Bullwhip Slope and Proportional Controller Inventory Instability Slope
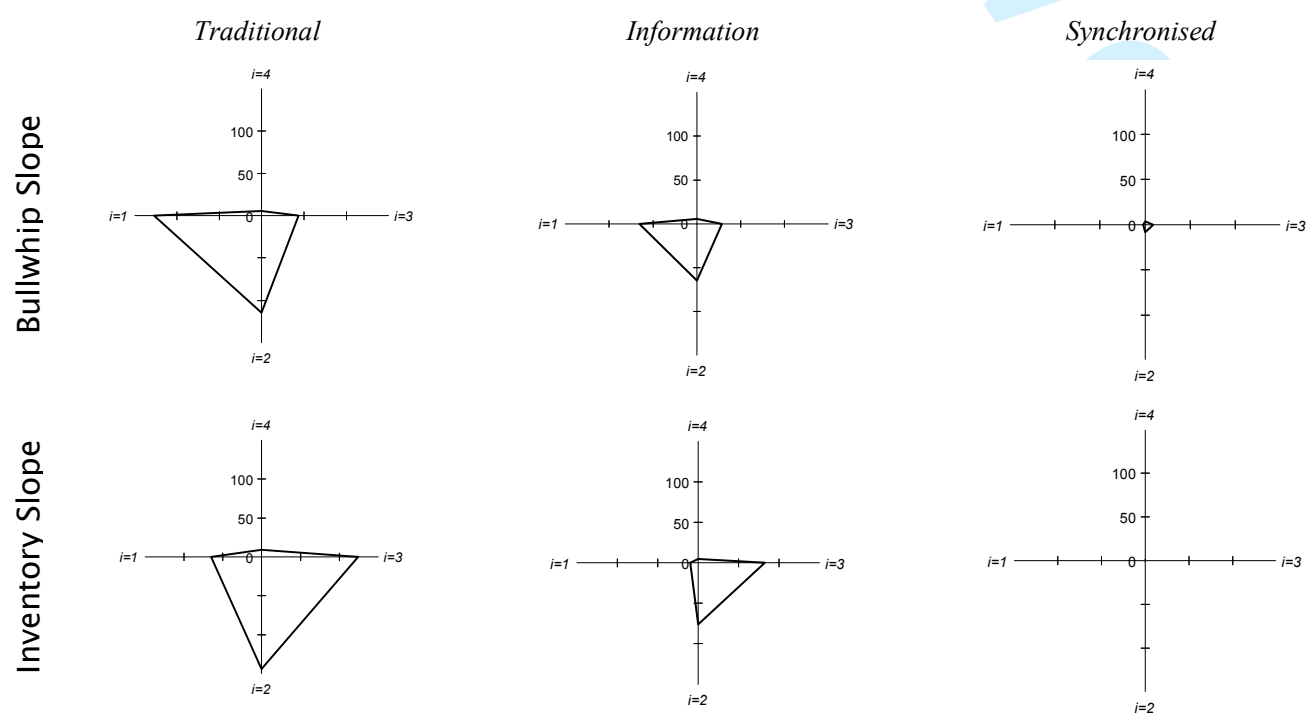
Figure 6. Average Inventory

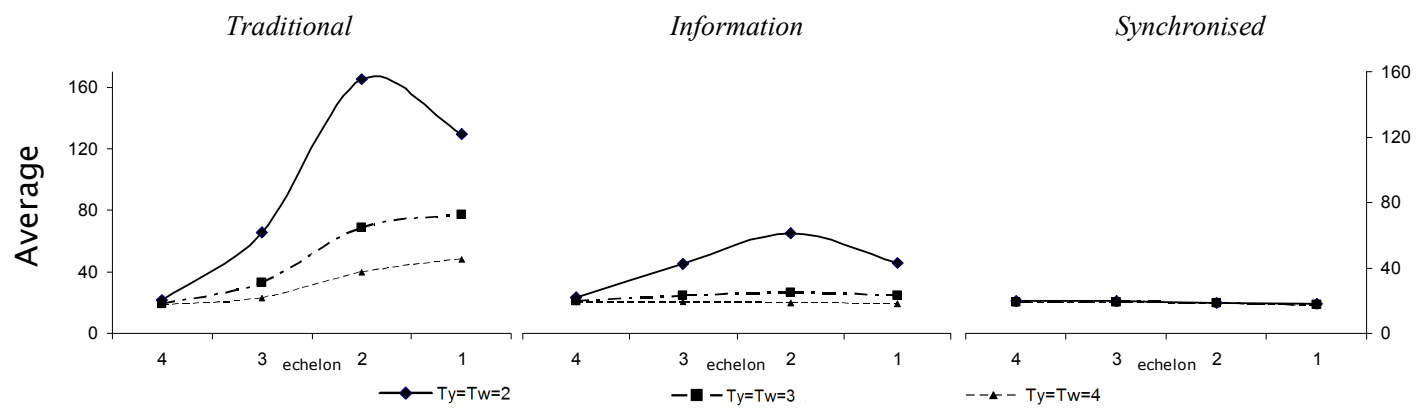

Figure 7. Zero-Replenishment
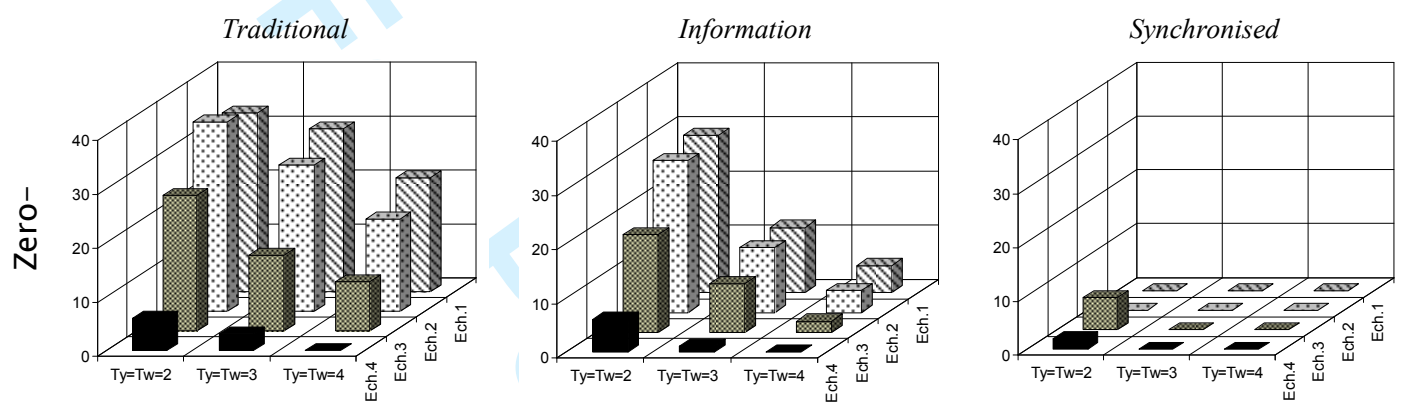

Figure 8. Average Fill Rate, Systemic Average Inventory, Systemic Zero-Replenishment

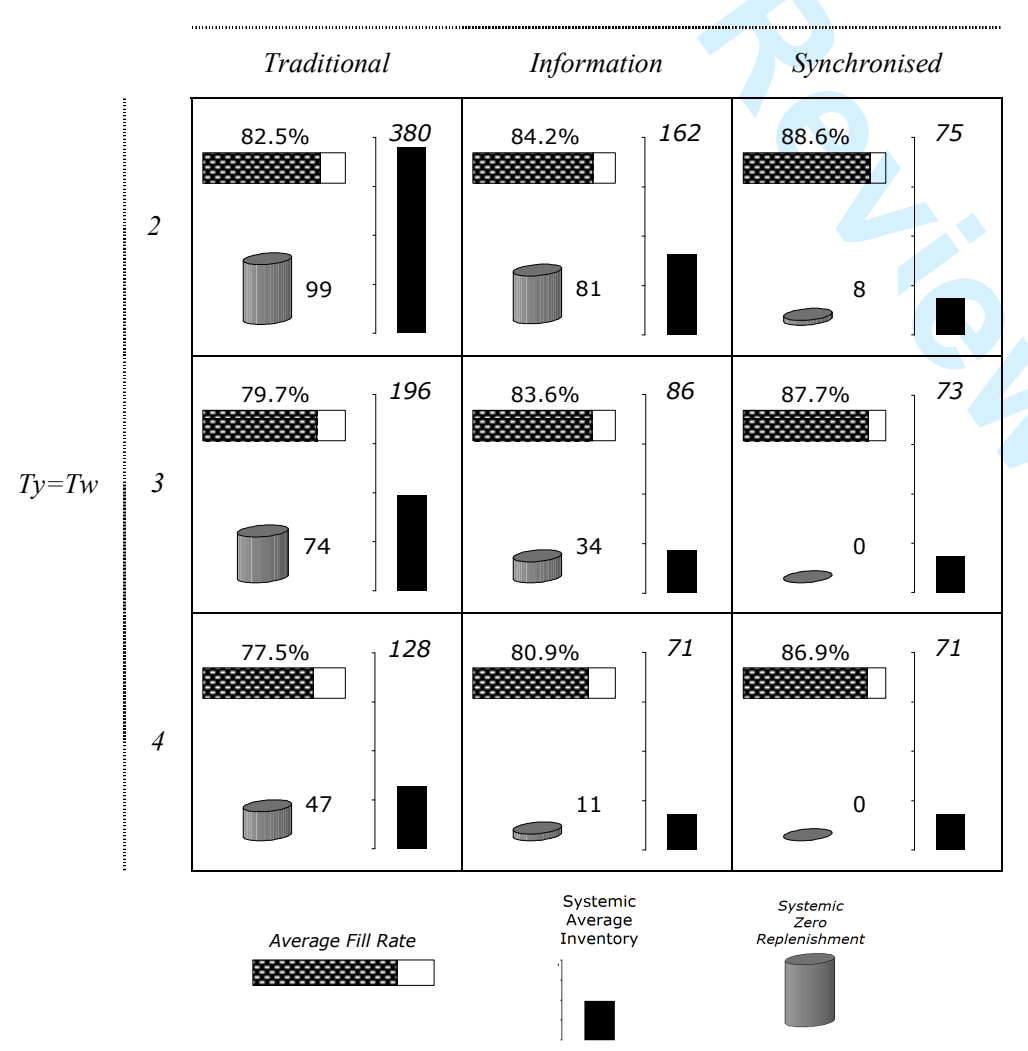


Figure 9. Impact of Supply Chain Collaboration and order smoothing on operational performance and customer service level

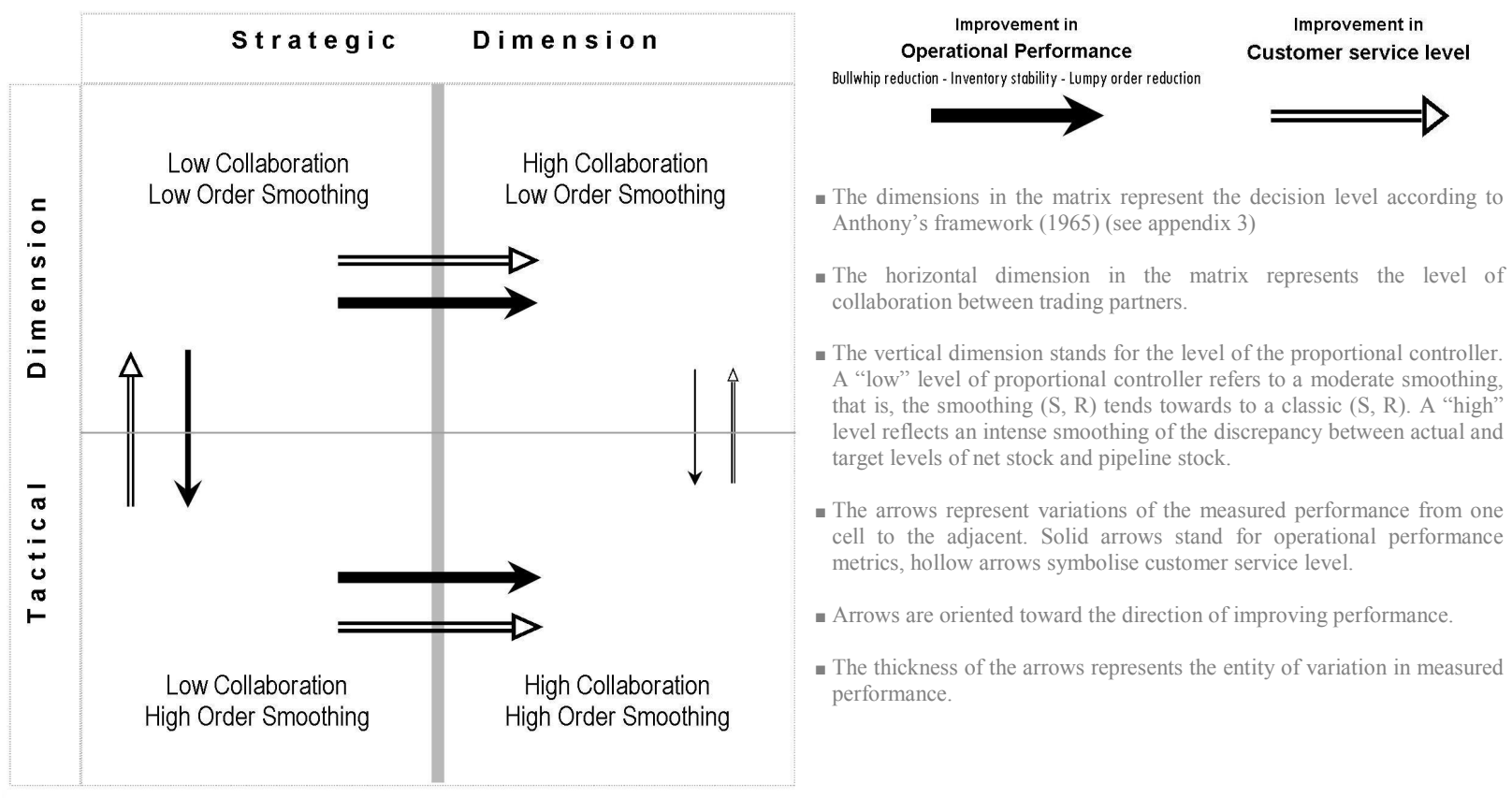

